Article

\title{
Optimized Lithological Mapping from Multispectral and Hyperspectral Remote Sensing Images Using Fused Multi-Classifiers
}

\author{
Mahendra Pal ${ }^{1,2, *}{ }^{\circ}$, Thorkild Rasmussen ${ }^{1}$ and Alok Porwal ${ }^{2}$ \\ 1 Division of Earth Science and Environmental Engineering, Department of Civil, Environmental and Natural \\ Resources Engineering, Luleå University of Technology, 97187 Luleå, Sweden; \\ thorkild.maack.rasmussen@ltu.se \\ 2 Center of Studies in Resources Engineering, Indian Institute of Technology Bombay, Mumbai 400076, India; \\ aporwal@iitb.ac.in \\ * Correspondence: mahendra.pal@ltu.se; Tel.: +46-(0)920-492434
}

Received: 2 December 2019; Accepted: 31 December 2019; Published: 3 January 2020

\begin{abstract}
Most available studies in lithological mapping using spaceborne multispectral and hyperspectral remote sensing images employ different classification and spectral matching algorithms for performing this task; however, our experiment reveals that no single algorithm renders satisfactory results. Therefore, a new approach based on an ensemble of classifiers is presented for lithological mapping using remote sensing images in this paper, which returns enhanced accuracy. The proposed method uses a weighted pooling approach for lithological mapping at each pixel level using the agreement of the class accuracy, overall accuracy and kappa coefficient from the multi-classifiers of an image. The technique is implemented in four steps; (1) classification images are generated using a variety of classifiers; (2) accuracy assessments are performed for each class, overall classification and estimation of kappa coefficient for every classifier; (3) an overall within-class accuracy index is estimated by weighting class accuracy, overall accuracy and kappa coefficient for each class and every classifier; (4) finally each pixel is assigned to a class for which it has the highest overall within-class accuracy index amongst all classes in all classifiers. To demonstrate the strength of the developed approach, four supervised classifiers (minimum distance (MD), spectral angle mapper (SAM), spectral information divergence (SID), support vector machine (SVM)) are used on one hyperspectral image (Hyperion) and two multispectral images (ASTER, Landsat 8-OLI) for mapping lithological units of the Udaipur area, Rajasthan, western India. The method is found significantly effective in increasing the accuracy in lithological mapping.
\end{abstract}

Keywords: remote sensing; hyperspectral; multispectral; Hyperion; ASTER; Landsat 8-OLI; classification; lithological mapping

\section{Introduction}

Mapping lithological units of an area using satellite-borne remote sensing data is one of the most challenging geological applications of remote sensing technology, given the complexities involving sub-pixel level microscopic-scale non-linear mixing of minerals and the presence of surface soil, regolith and vegetation. In addition, the limited data quality of available remote sensing images and restricted robustness in classification algorithms are the other factors leading lithological mapping more challenging. Most available studies employ different image classification and spectral matching algorithms for performing this task on available remote sensing images of the study area.

In general image classification is defined as a procedure of assigning class (category levels) to an image pixel. The image classification approaches in remote sensing are categorized in to two groups as 
unsupervised and supervised. Unsupervised classification techniques label category or class to an image pixel without the analyst's contribution whereas supervised classification techniques use the known markers as training samples (known) obtained from experts' knowledge to assign category or class to pixels of an image. There are various criteria developed for further subclassification of supervised and unsupervised techniques based on per-pixel and subpixel, soft and hard, parametric and nonparametric, and per-field [1]. Usually per-pixel classifiers create a signature by combining the entire pixels of the training set for a given class. Which can be parametric or non-parametric, soft or hard. In soft classifiers, classification decision boundary of the target is based on estimated conditional probability, whereas in hard classifiers, classification decision boundary of the target is estimated without making the probability assessment. In parametric classification approaches, it is assumed that the data are normally distributed, and estimated statistical parameters from the training samples represent the satisfactory population parameters. However, normal data distribution assumption in remote sensing images is often violated, especially the data captured from complex landscapes. In addition, ambiguity can be introduced in remote sensing image classification because of insufficient, non-representative, or multimode-distributed training samples. In additional, integration of ancillary information in parametric classifiers designed for remote sensing image classification is complicated. Maximum likelihood classifier is an example of parametric classifiers, which is one of the most widely used because of its robustness and easy implementation. On the contrary, in non-parametric classifiers, statistical parameters are not required to differentiate image pixels into different classes. In other word, condition of normal data distribution is not required in non-parametric classification approaches. Decision trees, expert systems, Support Vector Machine (SVM), deep learning and neural networks are typical examples of non-parametric classifiers which are widely preferred for classification remote sensing images from complex terrain [2-7]. Currently SVM, deep learning and neural networks-based algorithms are most widely being used because of its nonparametric technique and capability to distinguish complicated decision boundaries [8]. However, the performance of the neural network-based classifiers can be adversely affected due high dimensionality and unavailability of enough and satisfactory training and test samples of remote sensing images from complex terrains $[6,9]$. In recent years, bagging, boosting, or a hybrid of both techniques are being increasingly used to enhance the classification performance of non-parametric as well as parametric classifiers [6]. These methods have also been utilized in the framework of decision trees [10] and SVM [2,4,7,11-13] to enhance classifications accuracy.

Satellite-based hyperspectral data usually contain poor spatial resolution in order to maintain effective signal-to-noise ratio at narrow band widths. As a result, ground coverage comprised by an individual pixel in the image is practically large. Thus, most of the pixels are less likely to represent a pure spectrum and the pixel spectra are more likely to be combinations of the spectral responses from two or more types of materials (known as spectral mixing) [5,14-16]. Thus, identification and extraction of pure pixel spectra for training samples in the supervised classifier become a tedious task and critically affects the performance of the classifier. In particular, this problem become more difficult when the objective is to map lithological units, because each lithological unit itself comprises a non-linear microscopic-scale mixture of different minerals with distinct spectral signature. Typically, surface exposure of bed rock lithology of a survey area may partially cover under soil, regolith and vegetation, which further complicate the task. All these factors make lithological mapping one of the most challenging tasks using satellite-based remote sensing data.

Classification and mapping of lithological units from hyperspectral and multispectral data are typically carried out at the per pixel level using analytical techniques that involve either (1) matching a series of candidate spectra from a spectral library (field or laboratory) with the pixel spectra (image) or (2) using spectral parameters such as depths and symmetry of the absorption features, spectral slopes at specific wavelength, band ratios and so forth [17]. Subpixel level classification using above datasets is more difficult and still improvement needed in lithological mapping to due to nonlinearly spectral mixing. 
The following section describes some of the often-used algorithms for lithological classification from satellite-borne remote sensing data.

\section{Classification and Mapping Techniques}

Here we briefly review the most widely used classification techniques in geological applications.

\subsection{Whole Pixel Classification Approaches}

In whole pixels classification techniques, the entire pixel is assigned to a single class. In this section, most widely used in geological applications the different approaches in whole pixel classification are briefly provided.

\subsubsection{Based on Spectral Similarity Measures}

Spectral similarity measurement techniques calculate the similarity indices based on angle, correlation, divergence and Euclidean distance between reference and unknown spectra [18,19]. Based on the above spectral similarity measurements, developed approached are briefly explained below. (A) Spectral correlation measure

This technique calculates the spectral correlation between reference (known) spectrum to target (unknown) spectrum of an image. The spectral correlation $\left(r_{m}\right)$ between unknown pixel spectrum $\left(S_{i}=\left(S_{i 1}, \ldots, S_{i n}\right)^{T}\right)$ and a known spectrum $\left(S_{j}=\left(S_{j 1}, \ldots, S_{j n}\right)^{T}\right)$ is calculated as:

$$
r_{m}=\frac{n \sum S_{i} S_{j}-\sum S_{i} \sum S_{j}}{\sqrt{\left[n \sum S_{i}^{2}-\left(\sum S_{i}\right)^{2}\right]\left[n \sum S_{j}^{2}-\left(\sum S_{j}\right)^{2}\right]}}
$$

where $\sum$ stand for summation over $n$ number of overlapping spectral bands.

Spectral correlation is easy to compute. This measurement can be positive as well as negative. It incorporates both intensity and shape parameters of the spectra [20]. The problem with this technique is that it matches the entire spectrum with equal weight to all bands of the image irrespective of whether they contain diagnostic features for a specific geological material or not. As a result, erroneous spectral matching can be obtained due to even a small amount of spectral noise. Additionally, in making the classification, this technique is uncertain in objectively determining the threshold value $[20,21]$.

(B) Cross-correlogram spectral matching

Cross-correlogram spectral matching is an extension of spectral correlation technique [20-23]. The algorithm is implemented in the following sequential steps.

1. The reference spectra are extracted from either the image itself, measured in field or laboratory, or spectral library.

2. A correlogram is generated by calculating cross correlation between each reference spectrum and the unknown image pixel spectrum at different match positions $(m)$ by shifting the reference spectrum over successive channel position using the above Equation (1).

3. The statistical significance of the calculated cross-correlation coefficients is assessed by using the following $t$-test.

$$
t=r_{m} \sqrt{\frac{n-2}{1-r_{m}^{2}}}
$$

where $n$ is the number of overlapping spectral bands and $m$ the matching band number.

The $t$-values for the image are averaged from all image bands and rescaled to $0-1$. Further, the skewness of the image pixel correlogram is calculated and rescaled to $0-1$.

4. A data cube of cross-correlogram is constructed, and target material is mapped. The criteria for assigning the image pixel the reference material is that all the three parameters (namely significance, skewness and cross-correlation) are either equal or more than 0.9. This threshold value is arbitrary, which can be tuned according to the necessity and data quality. 
5. Finally, a Root Mean Square Error (RMSE) procedure based on the difference between the calculated pixel cross-correlogram and the ideal cross-correlogram calculated for the reference is used in order to assess the accuracy of the mapped target material as below:

$$
R M S E=\sqrt{\frac{\sum_{0}^{M} R_{M}-R_{M^{\prime}}}{N}}
$$

where $N$ and $M$ are the number of the match positions and the match number respectively, $R_{M}$ and $R_{M^{\prime}}$ are the pixel cross-correlation and the reference cross-correlation at match position $m$.

This technique is computationally simple and considers both overall shape and absorption intensity of the spectra. However, the major disadvantage of this technique is that it produces statistical match based on the individual absorption features. It is often found decline in match at the long-and-short-end of single materials spectrum values due to differences in albedo [21-23].

(C) Spectral angle measure

This technique is abbreviated as SAM, it evaluates the spectral angle between the image spectra and reference spectra. In this technique also the reference spectra of target materials are either extracted from the image itself or from spectral library (measured in field or laboratory) $[18,24,25]$. Mathematically this approach is demonstration below.

The reference spectrum $\left(S_{j}\right)$ and the pixel spectrum $\left(S_{i}\right)$ of the image are considered as vectors in an $n$ dimensional feature space. The spectral angle $(\theta)$ between the two vectors is easily determined using the dot product as follows:

$$
\theta=\cos ^{-1}\left(\frac{\vec{S}_{i} \cdot \vec{S}_{j}}{\left\|\vec{S}_{i}\right\| \cdot\left\|\vec{S}_{j}\right\|}\right) \stackrel{\text { or }}{\Rightarrow} \cos ^{-1}\left(\frac{\sum_{b=1}^{n} S_{i b} S_{j b}}{\sqrt{\sum_{b=1}^{n} S_{i b}^{2} \cdot \sqrt{\sum_{b=1}^{n} S_{j b}^{2}}}}\right)
$$

where $b$ is the number of bands. The similarity between the above two spectra is measured in terms of the spectral angle which is ranging from 0 (exactly similar) to $\pi / 2$ (entirely dissimilar) radians.

SAM is among one of the most widely used per-pixel-based supervised classification techniques for hyperspectral and multispectral remote sensing images in geological mapping [17]. This technique measures just the spectral angle characterized by the direction of the spectral feature vectors and entirely ignores the effects of albedo specified by the magnitude of the spectral feature vector. As a result, it is not affected by radiance illumination differences in the image. However, there is no standard procedure available for an unbiased selection of the threshold spectral angle for deciding in classification $[21,25,26]$.

(D) Euclidian distance measure

The Euclidian distance between two pixels spectral feature vectors in $n$ dimensional space is derived from the spectral angle measure as [21,27]:

$$
E D_{\left(S_{i}, S_{j}\right)}=2 \sqrt{1-\cos \left(\operatorname{SAM}\left(s_{i}, s_{j}\right)\right)=2 \sin \left(\frac{\operatorname{SAM}\left(s_{i}, s_{j}\right)}{2}\right)}
$$

where, $E D\left(S_{i}, S_{j}\right)$ is the Euclidian distance between $S_{i}$ and $S_{j} ; S_{i}=\left(S_{i 1}, \ldots, S_{i n}\right)^{T}$ is the test (image pixel) spectrum and $S_{j}=\left(S_{j 1}, \ldots, S_{j n}\right)^{T}$ is the reference (endmember or library) spectrum in the $n$ dimensional feature space respectively.

The main difference between SAM (and the spectral correlation) and Euclidian distance measure is that the spectral angle is invariant with brightness whereas the Euclidian distance considers the brightness difference between the two vectors [21,27].

(E) Spectral Information Divergence 
This is also a whole-pixel classification technique based on information theory, mostly abbreviated as SID. It discriminates the image pixels spectra $\left(S_{i}\right)$ based on spectral divergence with respect to reference spectra $\left(S_{j}\right)[28,29]$.

Mathematically, SID between $S_{i}$ and $S_{j}$ is calculated as below:

$$
\operatorname{SID}\left(S_{i}, S_{j}\right)=D\left(S_{i} \mid S_{j}\right)+D\left(S_{j} \mid S_{i}\right)
$$

where $D\left(S_{i} \mid S_{j}\right)=\sum_{k=1}^{n} p_{k} \log \left(\frac{p_{k}}{q_{k}}\right)$ the relative entropy of $S_{j}$ with respect to $S_{i}, D\left(S_{j} \mid S_{i}\right)=\sum_{k=1}^{n} q_{k} \log \left(\frac{q_{k}}{p_{k}}\right)$ the relative entropy of $S_{i}$ with respect to $S_{j}, p_{k}=\frac{S_{i_{k}}}{\sum_{k=1}^{n} S_{i_{k}}}$ and $p_{k}=\frac{S_{i_{k}}}{\sum_{k=1}^{n} S_{i_{k}}}$, where $k$ is the number of spectral band, $S_{i}=\left(S_{i 1}, \ldots, S_{i n}\right)^{\mathrm{T}}$ is the test (image pixel) spectrum and $S_{j}=\left(S_{j 1}, \ldots, S_{j n}\right)^{T}$ is the reference (endmember or library) spectrum in the $n$ dimensional feature space respectively.

The image pixels contain smaller spectral divergence are more likely close to the reference and higher spectral diversity are dissimilar to the reference. Spectral divergence of the image pixels greater than specified threshold are unclassified. SID can characterize spectral similarity and variability more effectively than SAM and ED. However, specifying the threshold value in this technique is critical and subjective to image quality and experts experience [28,29].

\subsubsection{Based on Derivative Absorption Band Parameters}

Absorption features in the reflectance spectra are considered as spectral fingerprints of geological materials in mineral and lithological mapping using remote sensing images. The above diagnostic spectral features are resulted from interaction of light to geological materials comprise of unique chemical compositions and crystallographic structures. A large number of reflectance and absorption based spectral parameters have been proposed in literature for identification and quantification of different geological materials from various multispectral and hyperspectral sensors, particularly those which contains diagnostic absorptions in the visible and near-infrared to shortwave infrared (VNIR-SWIR) regions (e.g., carbonates, clay minerals, olivine, pyroxenes, amphiboles etc.) [30-32]. These spectral parameters are mainly function of depth and locations of the absorption features, and consider other spectral features such as spectral symmetry of the absorption, slope between different wavelength bands, etc.

(A) Band ratio and relative absorption band-depth approach

Several approaches based on relative differences in distinct reflectance and absorption features have been developed for identification and mapping of different geological materials from hyperspectral and multispectral remote sensing images [19]. Based on above approaches, band ratio and band depth are the most widely used in geological mapping. Band ratio is mostly calculated over continuum removed spectra. A continuum removed spectrum $\left(R^{\prime}\right)$ is generated as follows:

$$
R^{\prime}=\frac{R}{R_{c}}
$$

where $R$ is the reflectance value for each point in the absorption feature, and $R_{c}$ is the reflectance level of continuum line at the corresponding wavelength [33-35]. Further, $R^{\prime}$ is rescaled between zero and one. Then Band Depth $(B D)$ is calculated from the $R^{\prime}$ as follows:

$$
B D=1-\frac{R^{\prime}}{R_{c}}
$$

Likewise, Band Depth Ratio $\left(B D_{r}\right)$ is computed by dividing the Band Depth $(B D)$ of each absorption feature by the highest band depth which is the band depth at the center of the absorption feature $\left(D_{c}\right)$ :

$$
B D_{r}=\frac{B D}{D_{c}}
$$


To minimize the influence of atmospheric effects, Bidirectional Reflectance Distribution Function (BRDF) effects and soil background, a normalization procedure can be applied on $B D_{r}$ on normalized continuum removed spectra [34]. Hence, a Normalized Band Depth Index $\left(N B D_{I}\right)$ has been developed as follows:

$$
N B D_{I}=\frac{B D-D_{c}}{B D+D_{c}}
$$

Further, for better quantification, band depth normalized to band area $\left(B D_{a}\right)$ is computed by dividing the Band Depth $(B D)$ of each channel of spectrum by the area of the absorption feature $\left(D_{a}\right)$ :

$$
B D_{a}=\frac{B D}{D_{a}}
$$

Few examples of relative absorption band-depth based techniques for geological materials discrimination and mapping are presented by Crowley et al. (1989) [36], Van Ruitenbeek et al. (2006) [37], Kopačková and Koucká (2017) [30], and Noori et al. (2019) [19].

In this subsection, the formulations for band ratio and relative absorption band-depth differ in different literatures. Therefore, we have used own formulation in order to establish uniformly.

(B) Spectral feature fitting method

The Spectral Feature Fitting (SFF) is an absorption feature based spectral matching technique. The steps involved in the SFF procedure are given below.

1. Removal of the continuum using a wavelength interval on each side of the absorption feature to be mapped from both target (field/library) and the unidentified (image) spectra.

2. Rescaling the target spectrum to match the scale of the unidentified spectrum and investigate the absorption features.

3. Calculation of apparent depth of absorption features with respect to respective continuum for both target and unidentified spectra.

4. Estimate the total RMSE and fit values between target and unidentified spectra.

A low RMSE and high fit-value approves to a good match between the unidentified and the target spectrum.

This approach has been widely used in a variety of mineral identification and geological mapping [30,38-41].

\subsection{Subpixel Classification Approaches}

It is very rare that pixels of hyperspectral remote sensing images are spectrally pure because of poor spatial resolutions. The requirement of spatial resolution (if a pixel of an image is normally a mixture of two or more target materials) in remote sensing image is relative in terms of their applications (e.g., $30 \mathrm{~m}$ spatial resolution of Hyperion image is considered good for land use and land cover mapping but poor for mineral and lithological mapping). Therefore, spectral unmixing techniques are indispensable for subpixel level spectral matching/mapping from the above images. There are basically two types of subpixel unmixing methods have been developed: linear and non-linear models. In linear unmixing models, the subpixel components are assumed to be physically distinct in terms of their reflectance, and hence the pixel's overall reflectance is a linear combination of reflectance of the different components within the pixel. On the other hand, non-linear unmixing models assume that the pixel components are intimately mixed at the microscopic levels and therefore in this approach it is believed that each photon of light undergoes multiple reflections. As a result, in nonlinear approaches overall reflectance from a mixed pixel cannot be considered a linear mixture from individual components. Subpixel classification techniques involve assigning label to the pixel into single or multiple class depending on the purity of the pixel. 


\subsubsection{Based on Linear Mixing Model/Linear Spectral Unmixing}

There are four basic assumptions involved in linear mixing modelling approaches [42]: (1) Each component within the image is spectrally distinct; (2) there are no multiple scattering between different components within the image; (3) all components or endmembers are known of the image; and; (4) the total abundance of individual components add to unity.

In the case of linear mixing models, spectra from a mixed pixel is considered as a linear weighted sum of individual endmember spectra proportional to the fractional area cover by respective endmember in the mixed pixel. Normally the output of linear spectral mixing analysis is produced in form of fraction images, with one fractional image for each endmember, which demonstrate the relative amount of the pixel area covered by that endmember.

Mathematically, linear unmixing model is explain as follows:

$$
R_{i}=\sum_{k=1}^{n} f_{k} R_{i k}+E R_{i} \text { and } \sum_{k=1}^{n} f_{k}=1
$$

where $i=1 \ldots m$ (number of spectral bands), $k=1 \ldots n$ (number of endmembers), $R_{i}$ is the spectral reflectance of the pixel in band $i, f_{k}$ is the proportion of the endmember $k$ within the pixel, $R_{i k}$ is the known spectral reflectance of endmember $k$ within the pixel on band $i, E R_{i}$ is the error for band $i$.

Model fit is assessed by $E R_{i}$ or using the following equations [43,44]:

$$
E R_{i}=\sqrt{\frac{\sum_{k=1}^{m}\left(\hat{I}_{k}-I_{k}\right)^{2}}{m}}
$$

Mean Absolute Error $(M A E)$,

$$
M A E=\frac{1}{m} \sum_{k=1}^{m}\left|I_{k}-\hat{I}_{k}\right|
$$

or correlation coefficient $\left(R^{2}\right)$,

$$
R^{2}=\frac{\sum_{k=1}^{m}\left|\overline{\hat{I}}_{k}-\bar{I}\right|}{\sum_{k=1}^{m}\left|I_{k}-\bar{I}\right|}
$$

where $\hat{I}_{k}$ is the estimated impervious surface fraction for sample $k, I_{k}$ is the impervious surface proportion computed from the images, $\bar{I}$ is the mean value of the samples, and $m$ is the number of samples.

\subsubsection{Based on Nonlinear Mixing Model/Nonlinear Spectral Unmixing}

In nonlinear mixing the photon of the light incident on a surface constituent interacts with multiple components before being detected by the sensor. There are various ways of interaction of photon from the mixed pixel in nonlinear mixing as: vertical mixing (e.g., tree canopies), horizontal mixing (e.g., granular mixtures) or both. Examples of nonlinear mixing include aerosols, atmospheric gases and particles, rocks, soils, vegetation and canopy.

There are various approaches in nonlinear mixing models which have been proposed in the literature. Nonlinear unmixing model developed by Hapke (1981) and Hapke (2012) [45-47] are most widely used which include microscopic mixing, and horizontal and vertical mixing. Many researchers have experimented with neural-network-based nonlinear spectral unmixing models $[6,8,15,48]$, post-nonlinear mixing models [49] and kernel-based models [50].

\subsection{Machine Learning and Deep Learning-based Techniques}

A variety of machine learning algorithms, including neural networks [6,51,52], SVM: unlike other algorithms it involves discriminating classes using linear hyperplanes. If the classes are not 
linearly separable in the feature space, they are projected to a higher dimension to ensure linear separability $[3,7,53,54]$, random forest (RF) $[55,56]$, have been widely applied to satellite image classification for various applications including mineral and lithological mapping [4]. All these algorithms involve learning the boundaries of different classes in the feature space based on the pre-classified training samples $[8,14,15]$.

Limited data quality of remote sensing images and complexities are involved in surface geology and restricted robustness of the above classifiers (Section 2) is leading to an ensemble-based technique using multi-classifiers in mineral and lithological mapping [6,15-17]. In general, a majority vote-based technique (MAXV) from multi-classifiers is used for boost target detection (lithological mapping) from remote sensing images. This approach is based on a majority vote scheme and the combined multi-classifiers with class receiving the largest number of votes at each pixel of an image. In fact, the MAXV method produces maximum value among the classifiers by approximately unbiased probability estimates for each class and overall classification. However, in lithological mapping, this approach is not always providing true results. Therefore, we developed a new approach for optimal classification with higher accuracies. It utilizes an ensemble of weighted pooling approaches at each pixel level; using agreement of the class accuracy, overall accuracy and kappa coefficient from the multi-classifiers. To demonstrate the strength of the developed approach, in this paper, four supervised classifiers (MD, SAM, SID, SVM) are used on a hyperspectral image (Hyperion) and two multispectral images (Advanced Spaceborne Thermal Emission and Reflection Radiometer (ASTER), Landsat 8 Operational Land Imager and Thermal Infrared Sensor (Landsat 8-OLI-TIRS)) for mapping of lithological units around the Udaipur area, Rajasthan, western India.

\section{Study Area and Datasets}

To verify the developed method in lithological mapping, Udaipur and nearby area from south-central part of Rajasthan state of India is selected as a geological test site. Geologically, the study area is mostly covered with metasedimentary litho-unit from the Aravalli supergroup ( $1800 \mathrm{Ma})$. Majorly representative rock units in the study are dolomite, greywacke, phyllite, quartzite, altered mafic metavolcanics, and intraformational conglome (defined as coarse-grained quartzite conglomerate by Geological Survey of India (GSI)) [57,58]. Additionally, test site belongs to dry and semi-arid condition and mostly terrain have good bedrock exposure. Further, area contain rugged topography with moderate to high rising hills, valleys and plains. Udaipur is rich with economic minerals and gemstones such as rock phosphate, lead-zinc, white and pink marbles, wollastonite, serpentinite (green marble), talc, calcite, barite, amphibole, asbestos, and pyrophyllite etc.

For testing the developed technique, Hyperion, ASTER and Landsat 8-OLI-TIRS images of an area around Udaipur city ( $24^{\circ} 6^{\prime} 56^{\prime \prime} \mathrm{N}: 24^{\circ} 54^{\prime} 45^{\prime \prime} \mathrm{N}$; $\left.73^{\circ} 32^{\prime} 51^{\prime \prime} \mathrm{E}: 73^{\circ} 48^{\prime} 38^{\prime \prime} \mathrm{E}\right)$ are selected (Figure 1).

Spaceborne high-resolution hyperspectral data with good data-quality are hardly available. Currently, Hyperion (spectral range of $0.4-2.5 \mu \mathrm{m}$ and bandwidth $\sim 10 \mathrm{~nm}$ ) aboard the Earth Observing-1 (EO-1) satellite from National Aeronautics and Space Administration's (NASA's) is the only source of spaceborne hyperspectral data. The availability of this data useful in mineral and lithological mapping is globally at limited locations only. In this study, a single strip of Hyperion image collected on January 19, 2004 from the study area is selected. The spatial and spectral resolutions of Hyperion are approximately $30 \mathrm{~m}$ and $10 \mathrm{~nm}$. It contain in total 242 bands with level-1 radiometrically corrected (L1R) data, among them only 198 bands are calibrated [8-57 for the visible and near-infrared (VNIR) and 77-224 for the shortwave infrared (SWIR)]; remaining 44 bands [1-8 from the VNIR and 225-242 from the SWIR] have poor signal due to their detector's low responsivity [59]. Further, there is an overlapping between the VNIR and SWIR bands [between bands 58-59 and 77-78], hence only 196 channels are unique. Furthermore, noisy bands due to atmospheric water absorption [bands 121-130 and 171-180] are removed, hence only remaining 176 bands are used for further study. 

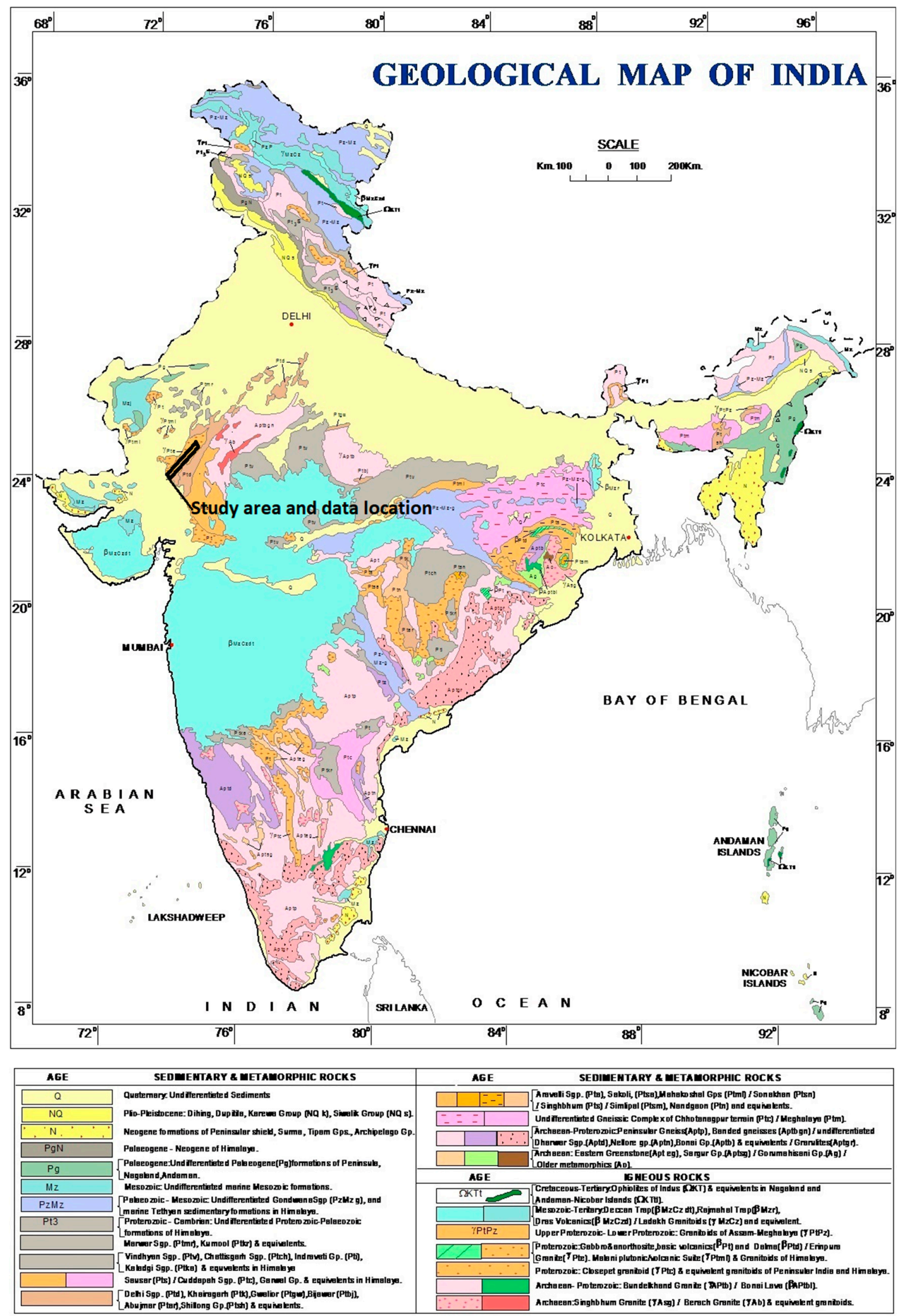

(a)

Figure 1. Cont. 


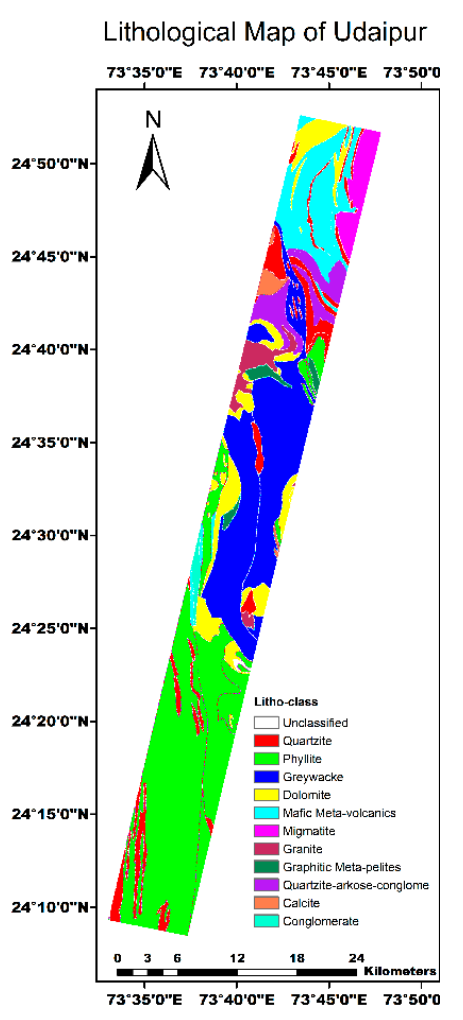

(b)

ASTER Image

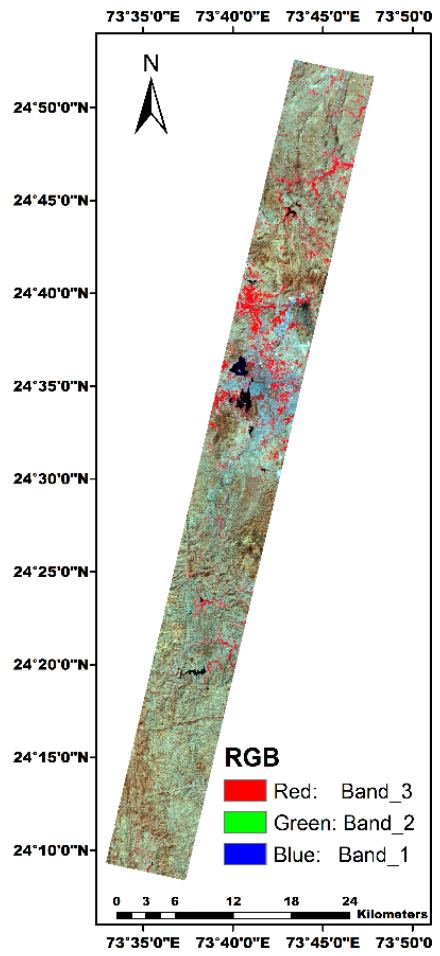

(d)
Hyperion Image

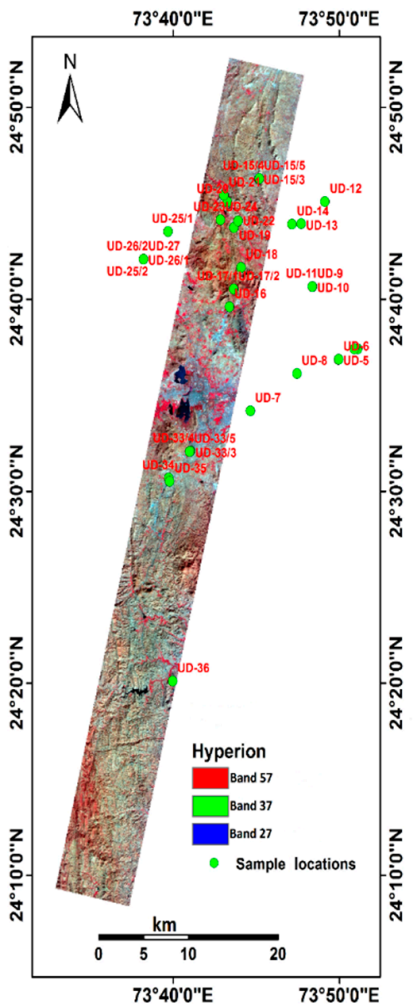

(c)

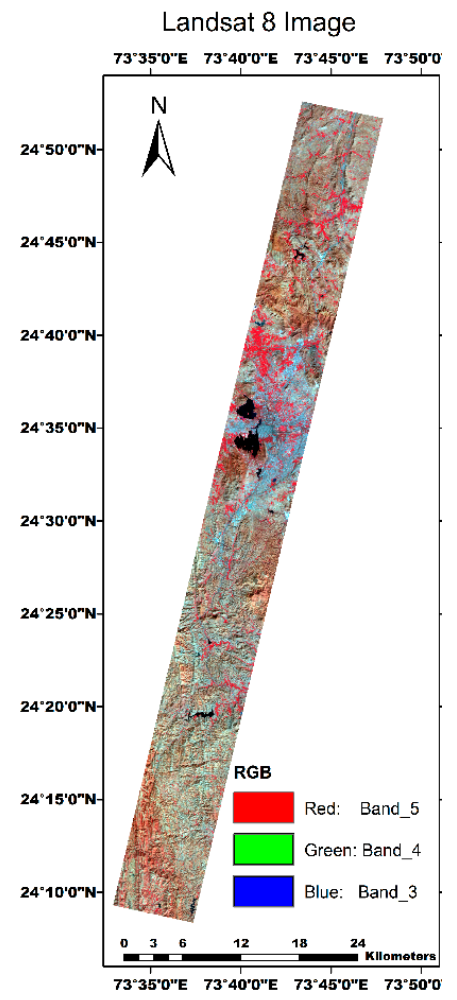

(e)

Figure 1. Study area and datasets: (a) Location, (b) bedrock lithology, (c) false color composite (FCC) image of Hyperion image with field sample collection and verification locations, (d) FCC image of ASTER, and (e) FCC image of Landsat 8. 
There are several multispectral remote sensing images available from different sources (e.g., NASA, European Space Agency (ESA), Indian Space Research Organization (ISRO)) to a study area for different applications (e.g., Land Use and Land Cover (LULC), geological mapping). In the present study, two multispectral images (ASTER and Landsat 8-OLI-TIRS) which are largely used in geological mapping are used to test the effectivity and efficiency of the developed technique.

An ASTER Level-1B dataset has been used as one of the multispectral images. It contains 14 bands from VNIR, SWIR and thermal infrared (TIR) spectral ranges with different spectral and spatial resolution [VNIR: band $1(0.520-0.60 \mu \mathrm{m})$, band $2(0.630-0.690 \mu \mathrm{m})$, band 3N $(0.760-0.860 \mu \mathrm{m})$ nadir, band 3B $(0.760-0.860 \mu \mathrm{m})$ backward with $15 \mathrm{~m}$ spatial resolution; SWIR: band $4(1.600-1.700 \mu \mathrm{m})$, band $5(2.145-2.185 \mu \mathrm{m})$, band $6(2.185-2.225 \mu \mathrm{m})$, band $7(2.235-2.285 \mu \mathrm{m})$, band $8(2.295-2.365 \mu \mathrm{m})$ and band $9(2.360-2.430 \mu \mathrm{m})$ with $30 \mathrm{~m}$ spatial resolution; and TIR: band $10(8.125-8.475 \mu \mathrm{m})$, band 11 $(8.475-8.825 \mu \mathrm{m})$, band $12(8.925-9.275 \mu \mathrm{m})$, band $13(10.250-10.950 \mu \mathrm{m})$ and band $14(10.950-11.650 \mu \mathrm{m})$ with $90 \mathrm{~m}$ spatial resolution].

To cover spatial ground location equivalent to Hyperion image of the study area, three daytime ASTER images are used which have been collected on February 12, 2008, March 2, 2008 and March 20, 2008.

Only VNIR and SWIR bands that coincides with the Hyperion spectral range have been considered for further processing. In addition, spatial resampling has been performed on visible bands to present all the bands with an approximately $30 \mathrm{~m}$ spatial resolution. Finally, nine bands from VNIR and SWIR bands [band $1(556 \mathrm{~nm})$, band $2(661 \mathrm{~nm})$, band $3(807 \mathrm{~nm})$, band $4(1656 \mathrm{~nm})$, band $5(2167 \mathrm{~nm})$, band 6 $(2209 \mathrm{~nm})$, band $7(2262 \mathrm{~nm})$, band $8(2336 \mathrm{~nm})$ and band $9(2400 \mathrm{~nm})]$ with $30 \mathrm{~m}$ spatial resolution of ASTER image, equivalent to Hyperion coverage. Furthermore, mosaic of available three ASTER images and their spatial subset (equivalent to Hyperion spatial ground location) were performed after atmospheric correction and used for further processing and studies.

Landsat 8 Level-1 Precision and Terrain (L1TP) corrected data is another multispectral image has been used in this study. Landsat 8 has a two-sensor payload; the Operational Land Imager (OLI) and the Thermal InfraRed Sensor (TIRS). Respectively, these two instruments collect image data for nine VNIR-SWIR bands and two longwave TIR bands [band $1(0.435-0.451 \mu \mathrm{m})$, band $2(0.452-0.512 \mu \mathrm{m})$, band $3(0.533-0.590 \mu \mathrm{m})$, band $4(0.636-0.673 \mu \mathrm{m})$, band $5(0.851-0.879 \mu \mathrm{m})$, band $6(1.566-1.651 \mu \mathrm{m})$ and band $7(2.107-2.294 \mu \mathrm{m})$ with $30 \mathrm{~m}$ spatial resolution; band $8(0.503-0.676 \mu \mathrm{m})$ panchromatic with $15 \mathrm{~m}$ spatial resolution; band $9(1.363-1.384 \mu \mathrm{m})$ with $30 \mathrm{~m}$ spatial resolution; band $10(10.60-11.19 \mu \mathrm{m})$ and band $11(11.50-12.51 \mu \mathrm{m})$ with $100 \mathrm{~m}$ spatial resolution].

In this study, daytime Landsat 8-OLI-TIRS collected on September 30, 2017 is selected. Only VNIR and SWIR bands overlaps with Hyperion spectral range have been considered for further processing. Among them, seven bands from the VNIR and SWIR spectral ranges [band 1 (443 nm), band 2 (482 nm), band $3(561 \mathrm{~nm})$, band $4(654 \mathrm{~nm})$, band $5(864 \mathrm{~nm})$, band $6(1608 \mathrm{~nm})$ and band $7(2200 \mathrm{~nm})]$ with $30 \mathrm{~m}$ spatial resolution of Landsat 8-OLI image have been selected. Further, spatial subset of Landsat 8 equivalent to Hyperion coverage has been selected after atmospheric correction for lithological mapping in this study.

The reflectance datasets have been obtained from all the above three datasets (Hyperion, ASTER and Landsat 8) after detailed radiometric and atmospheric corrections, before lithological mapping of the study area. The false color composite (FCC) images of the Hyperion, ASTER and Landsat 8 datasets after atmospheric correction are given in Figure 1c-e, respectively.

The study area has been mapped in detail by the GSI $[60,61]$ and we have collected bed rock lithological map from the same to assist our analysis. Further, we have done extensive field work to update and validate information on surface lithology. A bedrock geological map (Figure 1b) procured from the GSI [61] and in situ field verification have been performed for validating the results of lithological classification achieved from analysis of the multispectral and hyperspectral remote sensing images. In this study, refined GSI map and field verification were used as aid in selection of training pixels as well as for validation and assessment of classification accuracies. The location of the field 
is given in Figure 1a and corresponding bedrock geological map is provided in and Figure $1 \mathrm{~b}$ and sample collection and verification locations are provided in Figure 1c, respectively.

\section{Proposed Methodology}

In this paper, an ensemble classification technique is proposed for optimized lithological mapping of the study area from hyperspectral $\left(I_{H}\right)$ and/or multispectral $\left(I_{M}\right)$ and/or thematic $\left(I_{T}\right)$ remote sensing images using multi-classifiers. It is a weighted pooling-based mapping approach from multi-classifiers at each pixel level of an image using within-class accuracy: ability of classifier for a class; overall accuracy: strength of a classifier for classification; and kappa coefficient, which is the robustness of a classifier for an image. The flow diagram of the proposed method is shown in Figure 2.

Note: In this paper, we have experimented with one hyperspectral image as $I_{H} \rightarrow$ Hyperion and two multispectral images as $I_{M 1} \rightarrow$ ASTER and $I_{M 2} \rightarrow$ Landsat 8-OLI using four supervised classifiers as MD, SAM, SID and SVM.

The algorithm is implemented in the following steps.

Suppose any remote sensing image either hyperspectral, multispectral or thematic is represented as $I$.

Step 1. Generate classification images using multiple classifiers.

In this step, the input image is classified using $m$ number of classifiers $\left(f_{i}, i=1,2, \ldots, m\right)$ :

$$
I \stackrel{f_{i}}{\Rightarrow} C I_{f_{i}}
$$

where $I$ is the input remote sensing image and $C I_{f i}$ is the output classified image of the $i^{\text {th }}$ ( 1 to m) classifier.

Note: In this article, we have tested using four supervised classifiers: MD, SAM, SID and SVM. Thus, $C I_{f i}$ are $C I_{M D}, C I_{S A M}, C I_{S I D}, C I_{S V M}$ four classified images generated from each image respectively, where, $f_{1} \rightarrow \mathrm{MD}, f_{2} \rightarrow \mathrm{SAM}, f_{3} \rightarrow \mathrm{SID}$ and $f_{4} \rightarrow \mathrm{SVM}$.

Step 2. Accuracy assessments of classified images.

In this step, accuracy assessments are performed for classification results generated from different classifiers.

1. Within-class-accuracy for every class of each classified image is calculated for every classifier. Let $n$ be the numbers of classes and $C A_{i j}$ be the class accuracy of the $j^{\text {th }}$ class from the $i^{\text {th }}$ classifier.

2. The overall classification accuracy is calculated for each classifier. Let $O A_{i}$, be the overall accuracy of the $i^{\text {th }}$ classifier.

3. The kappa coefficient is calculated for each classifier. Let $\delta_{i}$, be the kappa value of the $i^{\text {th }}$ classifier.

Note that in the above steps, class accuracy and overall classification accuracies are calculated in percentage.

Step 3. Maximizing accuracy of classification.

The objective of this step is to combine classification results to obtain a hybrid classification image which has higher accuracy compared to the output classification images of the individual classifiers.

For every classifier, an overall-class-accuracy index $\left(O C A_{i j}\right)$ is obtained for each class as follows:

$$
O C A_{i j}=C A_{i j} \times O A_{i} \times \delta_{i}
$$

where, $j$ ( 1 to $n)$ is the class and $i$ ( 1 to $m$ ) is the classifier.

For every pixel, an overall-classification-accuracy index $\left(O C A_{i j}(x, y)\right.$ is generated for each class and for every classifier.

Further, the highest overall-classification-accuracy index $(M A X-O A I(x, y))$ among all classes and all classifiers is calculated for each pixel as follows:

$$
\operatorname{MAX}-\operatorname{OAI}(x, y)=\text { highest }\left\{O \operatorname{OCA}_{i j}(x, y)\right\}
$$


where $(x, y)$ is the pixel location or in other words $x$ and $y$ are the row number and column number, respectively, of the image pixel. A pixel is assigned to the class which has the accuracy index value equal to $M A X-O A I(x, y)$.

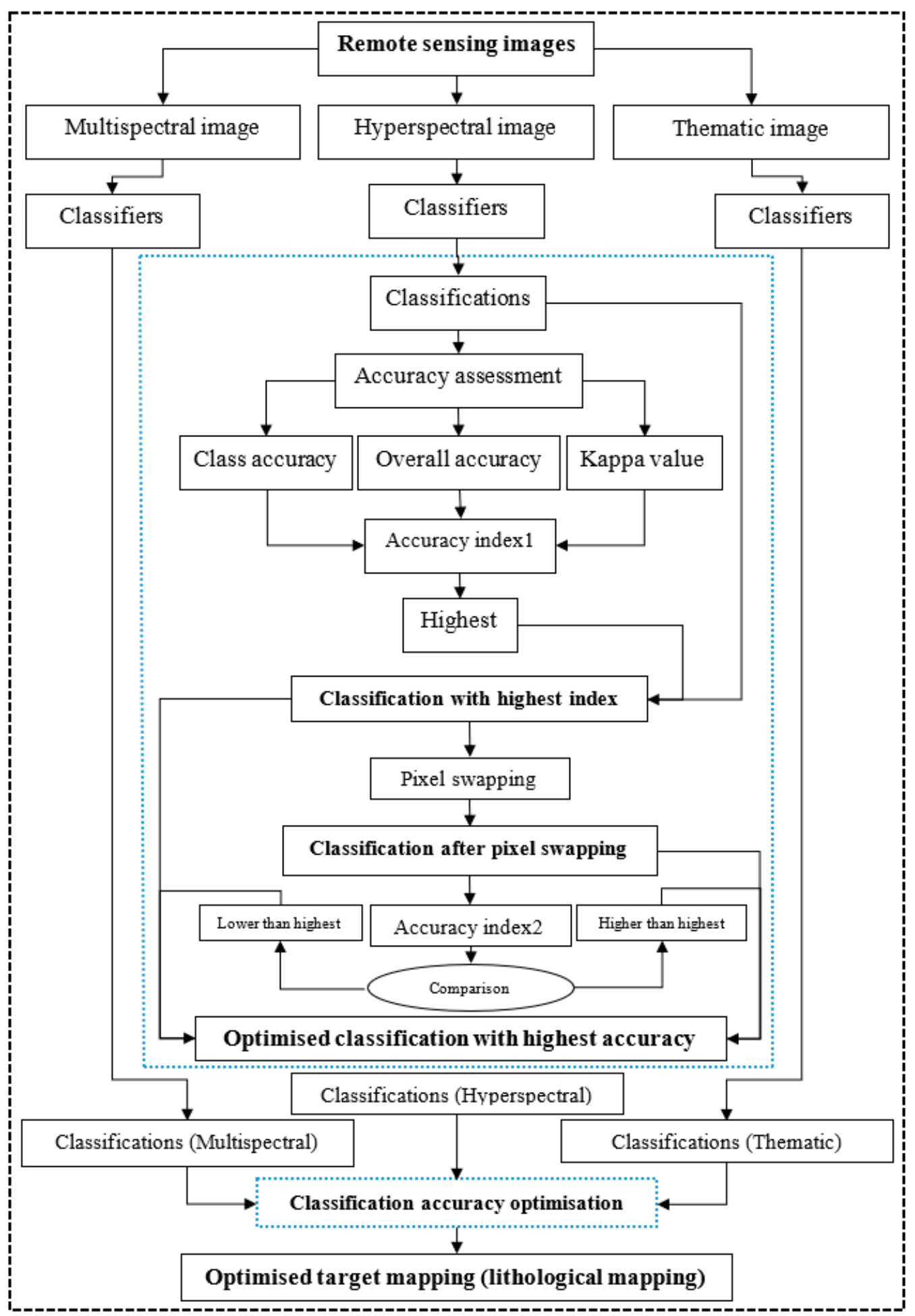

Figure 2. Flow diagram of proposed methodology for optimizing classification accuracy for lithological mapping using multi-classifiers. Note: In the procedure, the big dotted box represents the accuracy optimization process for hyperspectral data. The small dotted box represents the repetition of the process in the big dotted box, for combined classification from hyperspectral, multispectral and thematic images. 
Step 4. Optimizing classification accuracy.

In this step, pixel swapping is performed based on maximum frequency of nearest neighboring class (within $3 \times 3$ window-size) to generated fused classification result.

Further, accuracy assessment of the fused classification result after pixel swapping is performed.

Suppose $C A^{\prime}{ }_{j}$ is the class accuracy, $O A^{\prime}$ is the overall accuracy and $\delta^{\prime}$ is the kappa value of the fused classification result, then an overall-accuracy index $\left(M A X-O A I^{\prime}\right)$ of the fused classification image is obtained for each pixel of the image as follows:

$$
M A X-O A I^{\prime}(x, y)=C A_{j}^{\prime} \times O A^{\prime} \times \delta^{\prime}
$$

Now overall-accuracy index values are compared between $\left(M A X-O A I(x, y)\right.$ and $M A X-O A I^{\prime}(x, y)$ for each pixel. The class for the pixel after pixel swapping is accepted only if the index value $M A X-O A I^{\prime}(x, y)$ is more than $M A X-O A I(x, y)$.

Note: Pixel swapping using nearest neighboring pixels is applied here to rectify misclassified pixels due to spectrally similar geological materials and suppress misclassification due to nongeological influence in surface reflectance data.

According to the first law of geography, "all the things on the face of the earth are related to all other things but the near things are more related than distant things" [62]. Thus 'first law of geography' is the rationale behind the use of nearest neighboring pixels $(3 \times 3$ window size $)$ in the pixel swapping. In fact, surface lithology in real world is not equally exposed even with same subsurface bedrock lithology due to partially or fully contaminated by different degree of alteration and weathering and surface cover with nongeological materials. In the above case the nearest neighboring material signifies for the same.

Step 5. Generate optimized classification image.

The output optimized classification image is generated using the above steps (2-4) from classification images $\left(C_{f i}\right)$ generated in Step 1.

$$
\mathrm{CI}_{f_{i}} \stackrel{\text { classification accuracy optimization }}{\Longrightarrow} \mathrm{OCI}
$$

where $O C I$ is the optimized classification image with highest classification accuracy using $f_{i}$ classifiers from remote sensing image (I).

Step 6. Optimized classification image generation from multiple images.

Suppose hyperspectral remote sensing image is $I_{H}$, multispectral remote sensing image is $I_{M}$ and thematic remote sensing image is $I_{T}$, and classification results generated from the $f_{i}$ classifiers $(i=1,2$, $3 \ldots m)$ are $C I_{H i}, C I_{M i}$, and $C I_{T i}$, respectively, then final optimized classification result is generated from all the classification results generated from all the remote sensing images (e.g., $I_{H}, I_{M}$, and $I_{T}$ ) as:

$$
\left[I_{H_{i}}, I_{M_{i}}, I_{T_{i}} \stackrel{\text { classification accuracy optimization }}{\Longrightarrow} O C I_{H, M, T}\right.
$$

where the function 'classification accuracy optimization' includes the above steps $2-5$ applied among classification results, and $O C I_{H, M, T}$ is the final optimized classification result with highest accuracy generated from the $I_{H}, I_{M}$ and $I_{T}$ images.

Note: In this study area, we have experimented with multispectral and hyperspectral images only, because thematic image useful in lithological discrimination were not available. The idea behind putting thematic image in the proposed methodology is that the proposed method supports equally to thematic image in case lithological classification be able to achieve from the same of the study area.

\section{Results}

Prior to attempting the lithological classification of the hyperspectral (Hyperion) and the multispectral (ASTER, Landsat 8) remote sensing images, the pre-processing (noise reduction, 
radiometric correction, atmospheric correction) were performed to achieve reflectance data. The spectral subset and spatial resampling were performed on the ASTER and the Landsat 8, which cover bands in same spectral range (VNIR-SWIR) and to bring all the bands of images into the single spatial resolution $(30 \mathrm{~m})$, respectively. In addition, the areas covered completely by vegetation, surface alluvium, waterbodies, and built-up areas were masked.

The selection of training and validation pixels corresponding to different litho-classes in lithological mapping of unknown geology from coarse spectral resolution remote sensing images is still a challenging task. Thus far different litho-classes can be identified only by corresponding spectra from high spectral resolution data ( $10 \mathrm{~nm}$, hyperspectral) by judicious identification of spectral key features (absorption features and overall shape of the reflectance curve). In this study, the training and validation pixels for different litho-classes were selected from exposed bedrock by field visit and in situ verification (Figure 1c). The corresponding litho-classes were confirmed by field samples and bedrock geological map provided by GSI. Further, pure pixels were extracted with the help of pixel purity index from Hyperion image and corresponding litho-classes spectra were identified and selected for training and validation pixels from the study area. It's difficult to identify and validate different litho-classes from multispectral image (ASTER and the Landsat 8) spectra. Therefore, the training and validation pixels for different litho-classes from the ASTER and the Landsat 8 images were selected corresponding to the Hyperion identified litho-classes and the GSI bedrock lithological map from exposed terrain.

Subsequently, the following four supervised classifiers were used to classify the Hyperion, the ASTER and the Landsat 8 reflectance datasets. (1) MD—the Euclidean distance of each pixel spectrum to the mean spectrum of each lithological class in the feature space was estimated, and the pixel was assigned to the closest class. (2) SAM-the pixel and endmember spectra were plotted in feature space, and the pixel was assigned to the class with which it had minimum spectral angle, subject to the maximum of 0.10 radians. (3) SID-a divergence measure was used to match pixel spectrum to each endmember spectra, and the pixel was assigned to the class with which the divergence was minimum, subject to the maximum divergence of 0.05. (4) SVM-a radial basis kernel with Gamma $=0.05$ and penalty parameter $=100$ was used. Using the above classifiers, the MAXV (a majority of voting based ensemble method) classification is achieved.

In the further process, the described ensemble classification technique was implemented. For each classifier, within class accuracies were weighted by the overall classification accuracies and kappa coefficient of the respective classifier to obtain the overall class accuracy index. The classes were assigned to the pixels based on the overall class accuracy indices to generate ensemble classification with higher accuracies. The proposed method and the MAXV were applied to Hyperion, ASTER and Landsat 8 images separately as well as combined, respectively. The validation pixels for accuracies assessment of the lithological classification using above classifiers were selected from the lithological map prepared after GSI bed rock lithology tuned by field verification shown in Figure 1b corresponding to the common exposed bedrock in images (Hyperion, ASTER and Landsat 8) from the study area. The classification results are shown in Figure 3 and Table $1 \mathrm{a}$. Further, randomly three sets of training and test samples were collected for cross-validation of the classification models and the proposed method. The overall accuracy from each set of training and validation samples for all the classifiers along with the MAXV and the proposed method is shown in Table 1b. The results show that the proposed method effectively maximizes the classification accuracy by multi-classifiers in lithological mapping.

Further, image quality indices and spectral statistics have been analyzed to ascertain the influence of data quality and spectral distinctiveness of remote sensing images in addition to the robustness of classifiers in lithological mapping of a study area. 


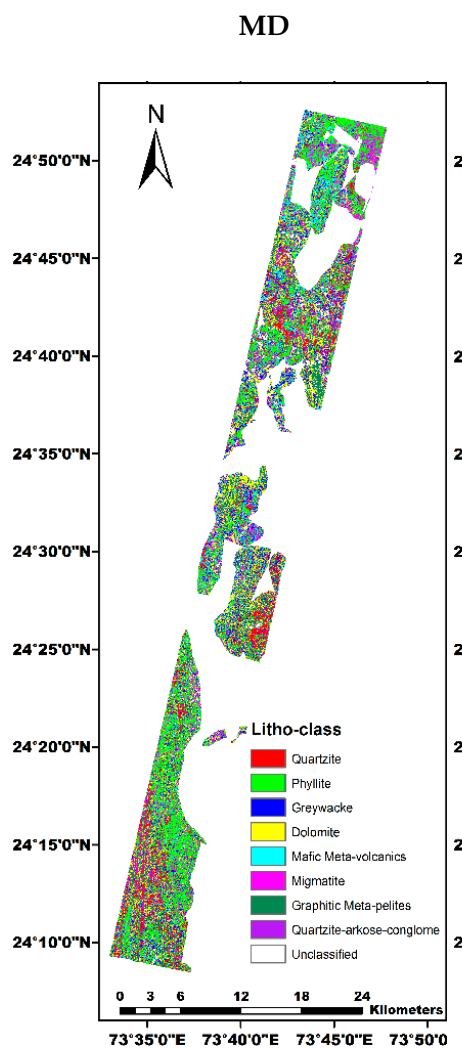

(a)

SVM

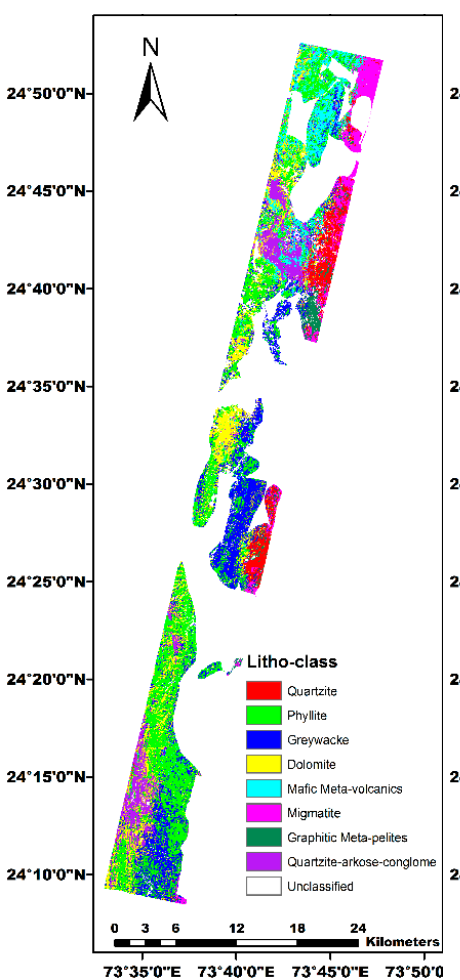

(d)
SAM

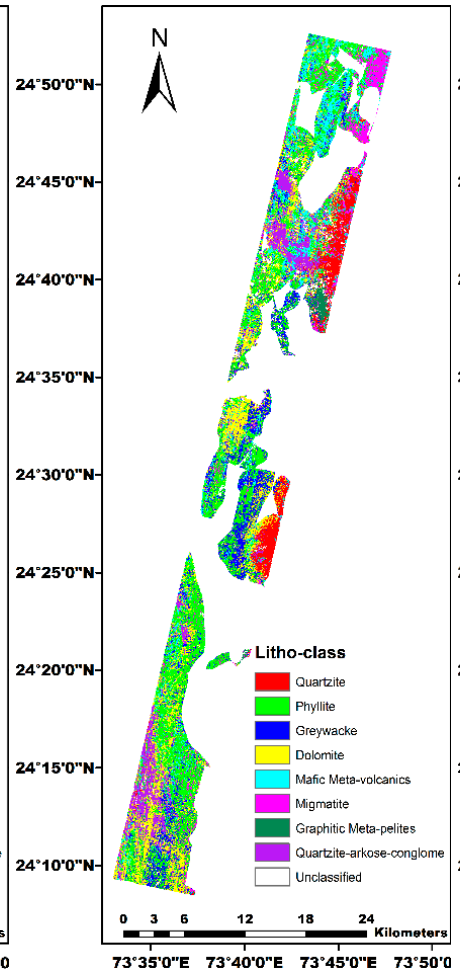

(b)

SID

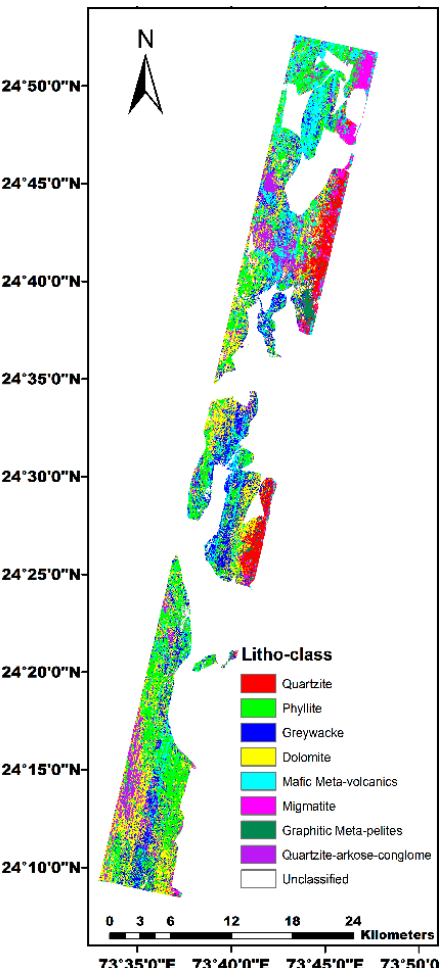

(c)

Proposed

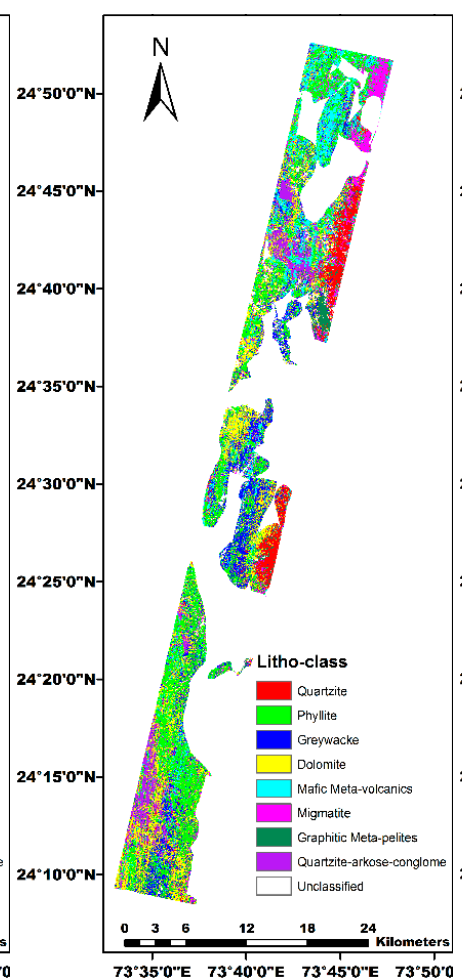

(e)

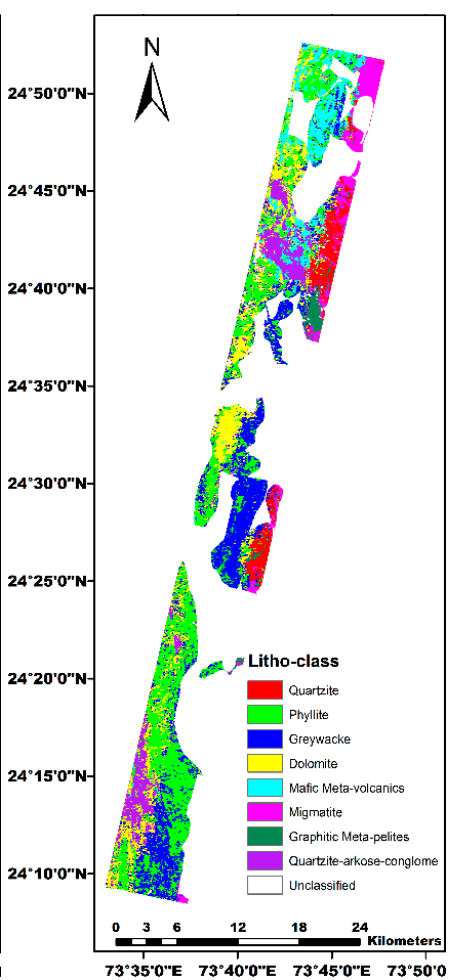

(f)

Figure 3. Cont. 
MD

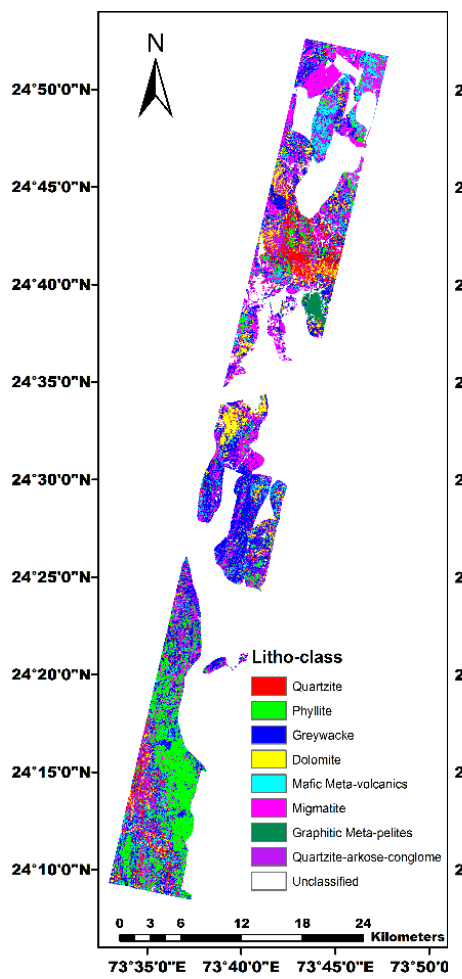

$\left(\mathbf{a}^{\prime}\right)$

SVM

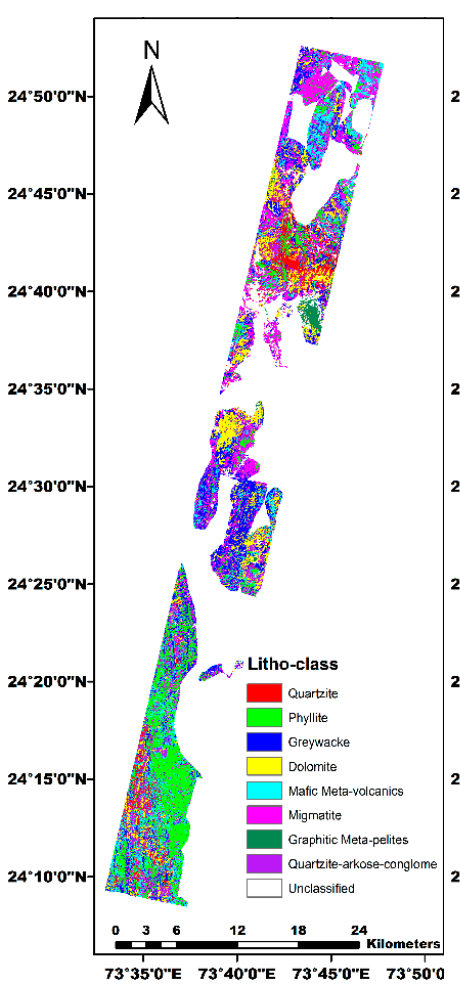

(d')
SAM

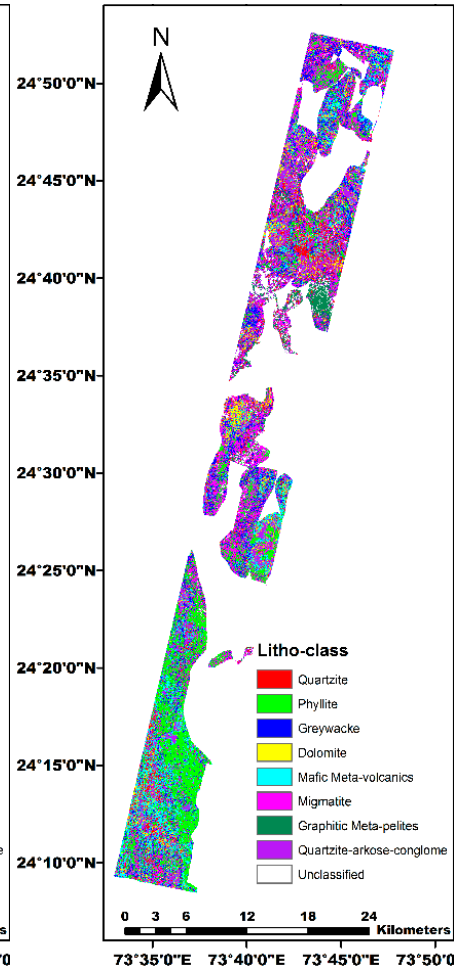

$\left(\mathbf{b}^{\prime}\right)$

MAXV

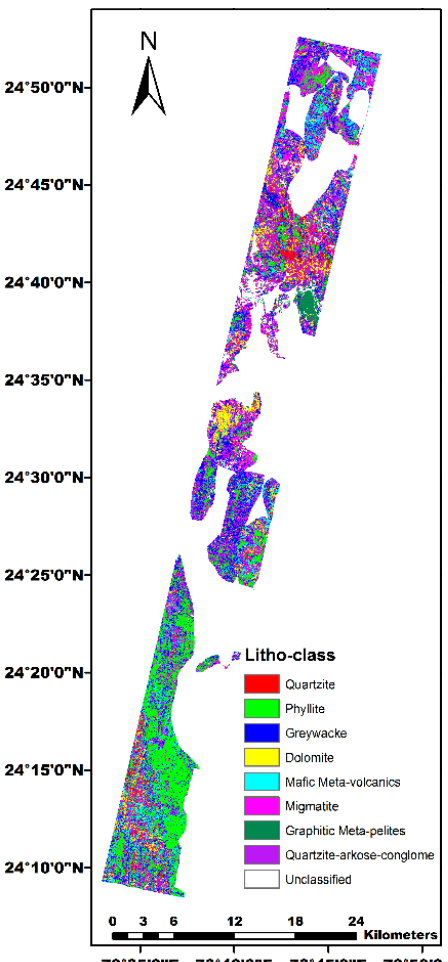

(e')
SID

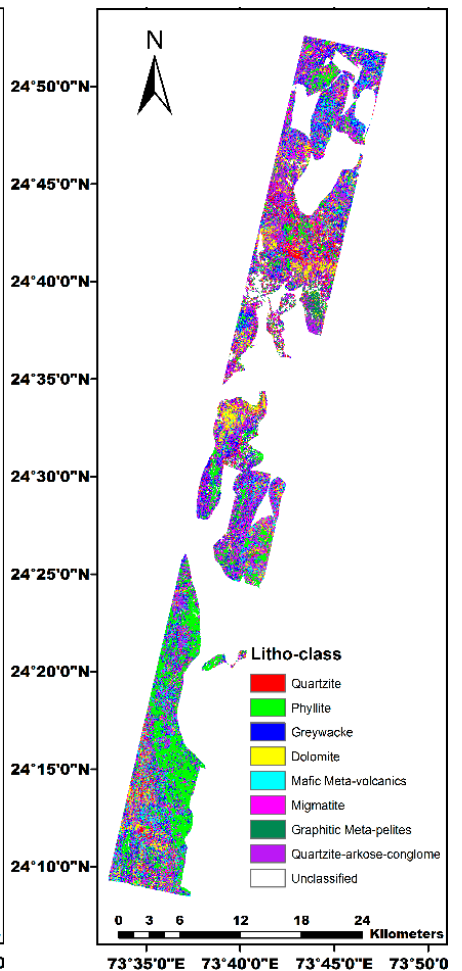

(c')

Proposed

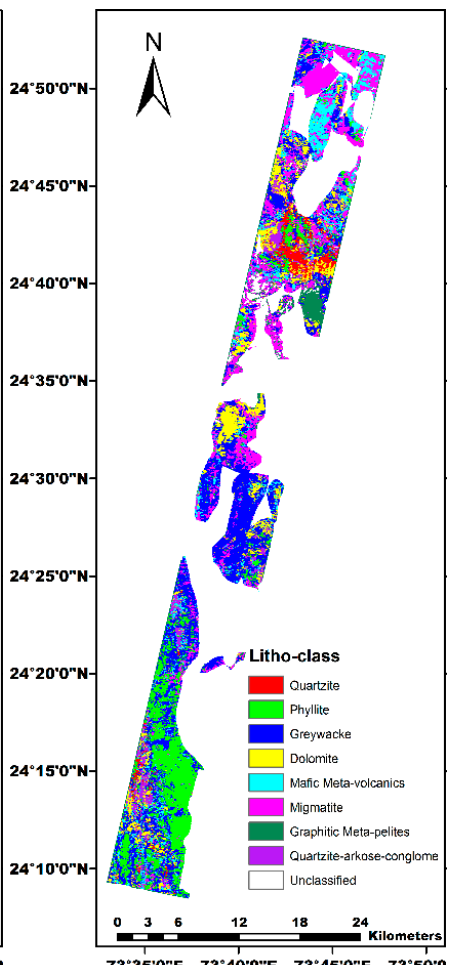

$\left(\mathbf{f}^{\prime}\right)$

Figure 3. Cont. 
MD

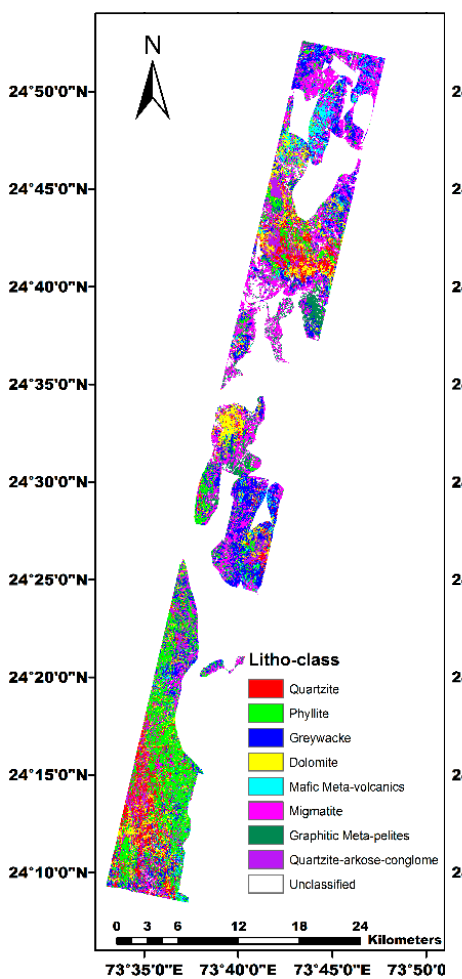

$\left(\mathbf{a}^{\prime \prime}\right)$

SVM

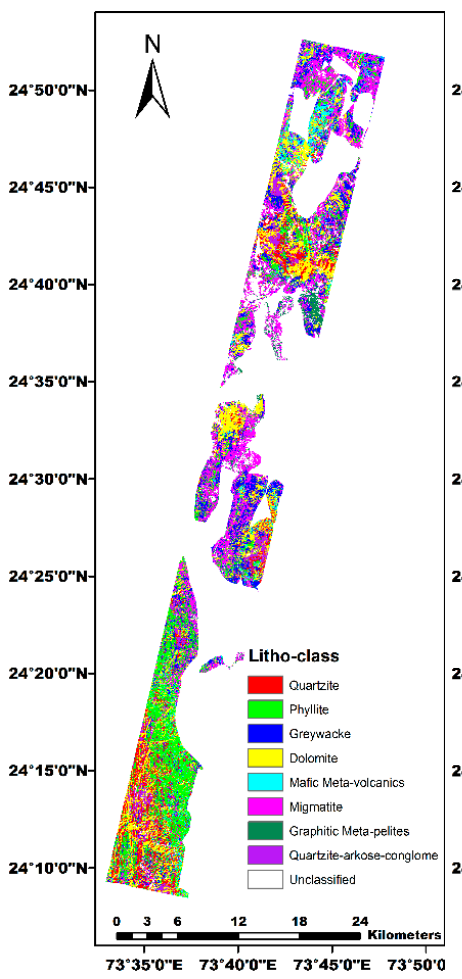

$\left(d^{\prime \prime}\right)$
SAM

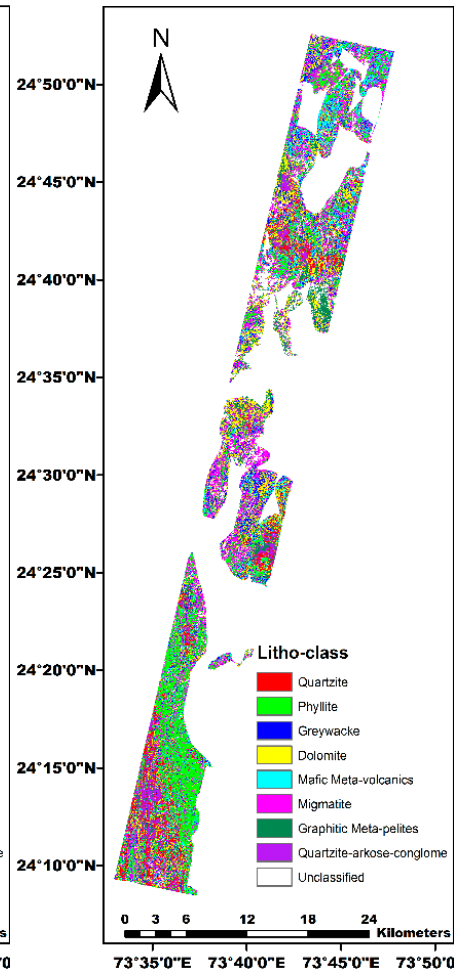

$\left(\mathbf{b}^{\prime \prime}\right)$

MAXV

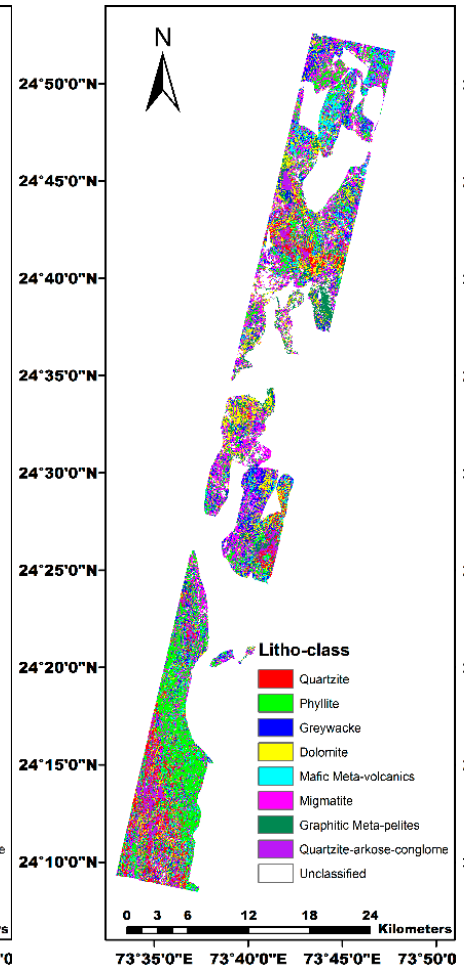

$\left(\mathrm{e}^{\prime \prime}\right)$
SID

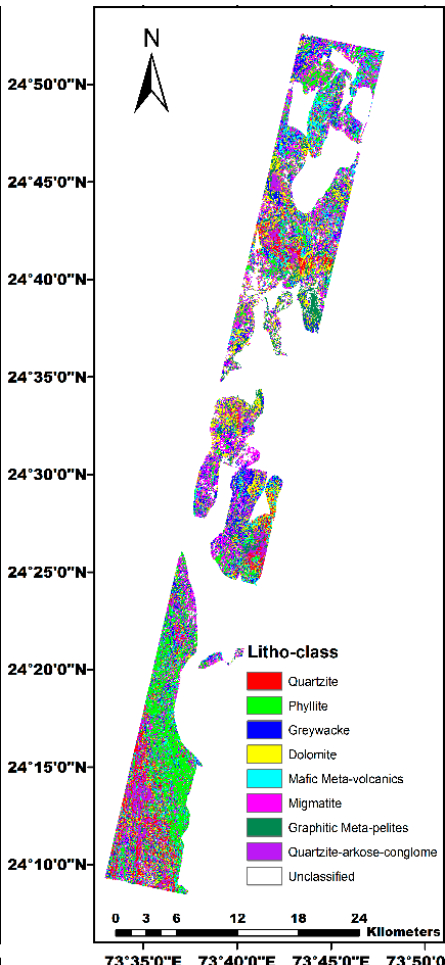

$\left(c^{\prime \prime}\right)$

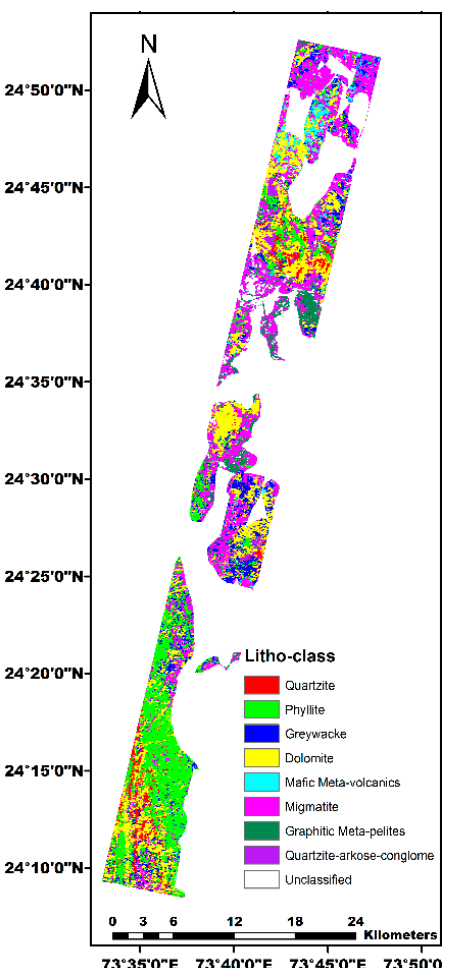

$\left(\mathbf{f}^{\prime \prime}\right)$

Figure 3. Cont. 


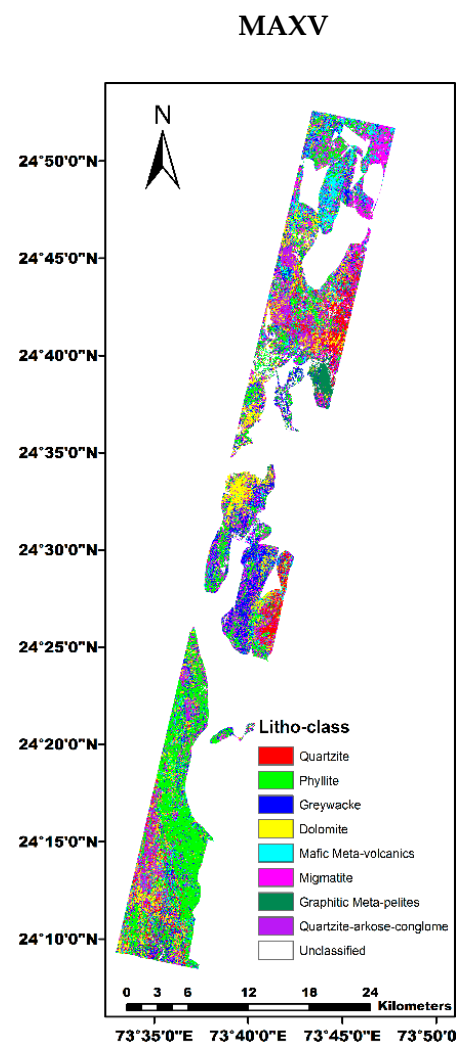

$\left(\mathrm{e}^{\prime \prime \prime}\right)$

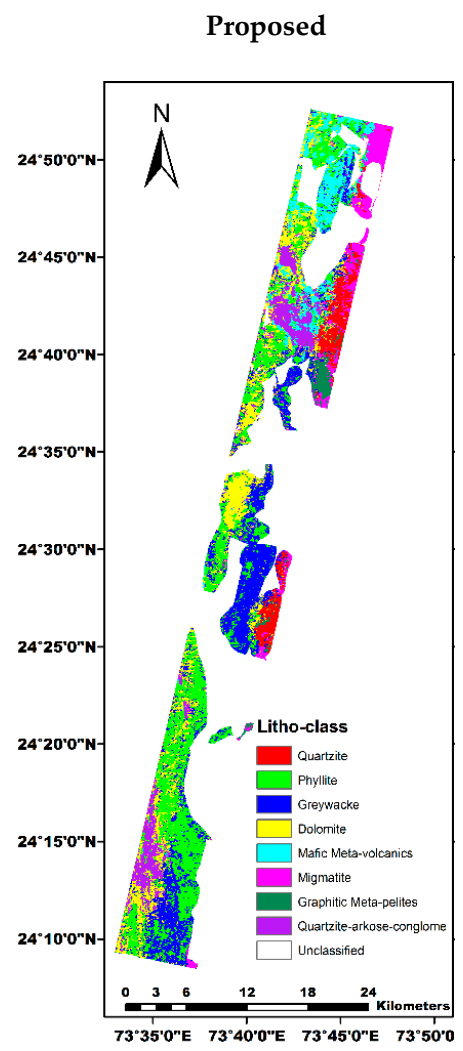

$\left(\mathbf{f}^{\prime \prime \prime}\right)$

Figure 3. Lithological mapping, using Hyperion image by MD (a), SAM (b), SID (c), SVM (d), MAXV (e), and proposed method (f); using ASTER image by MD $\left(\mathbf{a}^{\prime}\right), \operatorname{SAM}\left(\mathbf{b}^{\prime}\right), \operatorname{SID}\left(\mathbf{c}^{\prime}\right), \operatorname{SVM}\left(\mathbf{d}^{\prime}\right), \operatorname{MAXV}\left(\mathbf{e}^{\prime}\right)$, and proposed method $\left(\mathbf{f}^{\prime}\right)$; using Landsat 8 image by MD $\left(\mathbf{a}^{\prime \prime}\right), \operatorname{SAM}\left(\mathbf{b}^{\prime \prime}\right)$, SID $\left(\mathbf{c}^{\prime \prime}\right)$, SVM $\left(\mathbf{d}^{\prime \prime}\right)$, MAXV $\left(\mathbf{e}^{\prime \prime}\right)$, and proposed method $\left(\mathbf{f}^{\prime \prime}\right)$; and using combined (Hyperion, ASTER, and Landsat 8) images by $\operatorname{MAXV}\left(\mathbf{e}^{\prime \prime \prime}\right)$ and proposed method $\left(\mathbf{f}^{\prime \prime \prime}\right)$ of the study area.

The average image quality indices (signal to noise ratio and Shannon's entropy) calculated from Hyperion, ASTER and Landsat 8 images are shown in Table 2. Signal to noise ratio $(S: N)$ is defined as the ratio of maximum signal strength to the background noise present in an image [63]. A local variance method is used to estimate signal to noise ratio using the following formula:

$$
S: N=20 \log _{10} \times\left(\frac{\text { Mean }_{H}}{\text { RSM }_{\text {error }}}\right)
$$

where $\mathrm{Mean}_{H}$ and $R S M_{\text {error }}$ are average signal value and square root of the mean of the variances, respectively, of a completely homogenous portion of the image. Shannon's entropy $(H)$ is one way to represent information entropy, which measures the richness of the information quantity in an image [64]. It is calculated using the following equation:

$$
H=-\sum_{i=1}^{M} P_{i} \log P_{i}
$$

In the above equation, $i$ and $P_{i}$ denote the image's grey value and the probability of grey value $I$, respectively. Note: Average signal to noise ratio and Shannon's entropy calculated from all the bands of the Hyperion, ASTER and Landsat 8 images, respectively, are shown in Table 2.

Further, in Figure 4 and Table 3, the average spectral profiles and spectral statistics of different lithological units extracted from Hyperion in Figure 4a, ASTER in Figure $4 \mathrm{~b}$ and Landsat 8 in Figure 4c from the study area are shown. 
Table 1. (a) Classification accuracy assessment. (b) Cross-validation overall accuracy (\%) for classification accuracy assessment.

\begin{tabular}{|c|c|c|c|c|c|c|c|c|c|c|}
\hline \multicolumn{9}{|c|}{ Hyperion } & & \\
\hline $\begin{array}{l}\text { Lithoclass/ } \\
\text { classifier }\end{array}$ & Quartzite & Phyllite & Greywacke & Dolomite & $\begin{array}{l}\text { Mafic-meta- } \\
\text { volcanics }\end{array}$ & Migmatite & $\begin{array}{l}\text { Graphitic } \\
\text { meta-pelites }\end{array}$ & $\begin{array}{c}\text { Quartzite- } \\
\text { arkose-conglome }\end{array}$ & \multirow{3}{*}{$\begin{array}{c}\text { Overall } \\
\text { accuracy (\%) }\end{array}$} & \multirow{3}{*}{$\begin{array}{c}\text { kappa } \\
\text { coefficien }\end{array}$} \\
\hline No. of training pixels & 159 & 167 & 116 & 110 & 148 & 184 & 109 & 152 & & \\
\hline No. of test pixels & 979 & 1127 & 926 & 1289 & 1112 & 648 & 1500 & 994 & & \\
\hline MD (\%) & 49.31 & 62.73 & 31.03 & 40.81 & 45.1 & 70.63 & 91.28 & 28.75 & 48.30 & 0.41 \\
\hline SAM (\%) & 70.27 & 64.23 & 54.33 & 81.87 & 71.59 & 82.53 & 91.25 & 73.33 & 71.11 & 0.67 \\
\hline SID (\%) & 74.81 & 47.89 & 55.11 & 56.5 & 79.17 & 89.63 & 89.32 & 65.47 & 65.91 & 0.61 \\
\hline SVM (\%) & 88.93 & 76.17 & 87.44 & 88.93 & 82.52 & 96.9 & 95.04 & 85.49 & 86.54 & 0.84 \\
\hline MAXV (\%) & 74.44 & 61.67 & 57.18 & 68.04 & 77.11 & 89.8 & 93.19 & 69.06 & 70.58 & 0.66 \\
\hline Proposed (\%) & 90.4 & 81.44 & 96.47 & 96.63 & 89.8 & 99.23 & 95.11 & 87.58 & 91.56 & 0.90 \\
\hline \multicolumn{11}{|c|}{ ASTER } \\
\hline $\begin{array}{l}\text { Lithoclass/ } \\
\text { classifier }\end{array}$ & Quartzite & Phyllite & Greywacke & Dolomite & $\begin{array}{l}\text { Mafic-meta- } \\
\text { volcanics }\end{array}$ & Migmatite & $\begin{array}{c}\text { Graphitic } \\
\text { meta-pelites }\end{array}$ & $\begin{array}{c}\text { Quartzite- } \\
\text { arkose-conglome }\end{array}$ & \multirow{3}{*}{$\begin{array}{c}\text { Overall } \\
\text { accuracy (\%) }\end{array}$} & \multirow{3}{*}{$\begin{array}{c}\text { kappa } \\
\text { coefficient }\end{array}$} \\
\hline No. of training pixels & 135 & 128 & 98 & 92 & 132 & 126 & 84 & 118 & & \\
\hline No. of test pixels & 979 & 1127 & 926 & 1289 & 1112 & 648 & 1500 & 994 & & \\
\hline MD (\%) & 52.66 & 73.43 & 52.77 & 79.5 & 63.06 & 88.17 & 94.49 & 58.89 & 67.31 & 0.62 \\
\hline SAM (\%) & 28.08 & 62.79 & 27.57 & 43.02 & 38.92 & 39.27 & 92.45 & 46.26 & 44.14 & 0.36 \\
\hline $\operatorname{SID}(\%)$ & 23.71 & 64.05 & 24.6 & 51.61 & 30.18 & 41.49 & 71.32 & 44.8 & 42.17 & 0.34 \\
\hline SVM $(\%)$ & 46.35 & 74.79 & 43.42 & 86.2 & 52.76 & 83.23 & 94.92 & 52.07 & 63.60 & 0.58 \\
\hline MAXV (\%) & 32.99 & 68.61 & 35.9 & 64.37 & 48.18 & 59.46 & 94.67 & 48.26 & 53.46 & 0.47 \\
\hline Proposed (\%) & 54.41 & 81.21 & 61.6 & 94.22 & 84.91 & 92.72 & 95.12 & 60.68 & 75.68 & 0.72 \\
\hline \multicolumn{11}{|c|}{ Landsat 8} \\
\hline $\begin{array}{l}\text { Lithoclass/ } \\
\text { classifier }\end{array}$ & Quartzite & Phyllite & Greywacke & Dolomite & $\begin{array}{l}\text { Mafic-meta- } \\
\text { volcanics }\end{array}$ & Migmatite & $\begin{array}{c}\text { Graphitic } \\
\text { meta-pelites }\end{array}$ & $\begin{array}{c}\text { Quartzite- } \\
\text { arkose-conglome }\end{array}$ & \multirow{3}{*}{$\begin{array}{c}\text { Overall } \\
\text { accuracy (\%) }\end{array}$} & \multirow{3}{*}{$\begin{array}{c}\text { kappa } \\
\text { coefficien }\end{array}$} \\
\hline No. of training pixels & 138 & 134 & 108 & 98 & 124 & 142 & 96 & 136 & & \\
\hline No. of test pixels & 979 & 1127 & 926 & 1289 & 1112 & 648 & 1500 & 994 & & \\
\hline $\mathrm{MD}(\%)$ & 58.64 & 53.94 & 62.86 & 74.32 & 55.19 & 87.24 & 92.64 & 49.01 & 63.78 & 0.58 \\
\hline SAM (\%) & 50.78 & 57.86 & 29.65 & 44.46 & 32.94 & 46.63 & 93.28 & 40.29 & 46.14 & 0.38 \\
\hline SID (\%) & 49.31 & 55.21 & 38.95 & 40.21 & 36.74 & 46.63 & 93.46 & 44.01 & 47.46 & 0.40 \\
\hline SVM (\%) & 56.39 & 59.09 & 49.35 & 80.51 & 41.46 & 76.92 & 92.82 & 43.11 & 59.72 & 0.54 \\
\hline MAXV (\%) & 52.43 & 56.75 & 41.18 & 49.6 & 39.34 & 51.92 & 93.69 & 43.35 & 50.59 & 0.43 \\
\hline Proposed (\%) & 54.76 & 65.49 & 57.33 & 97.27 & 46.58 & 92.8 & 95.04 & 46.1 & 66.79 & 0.62 \\
\hline
\end{tabular}


Table 1. Cont

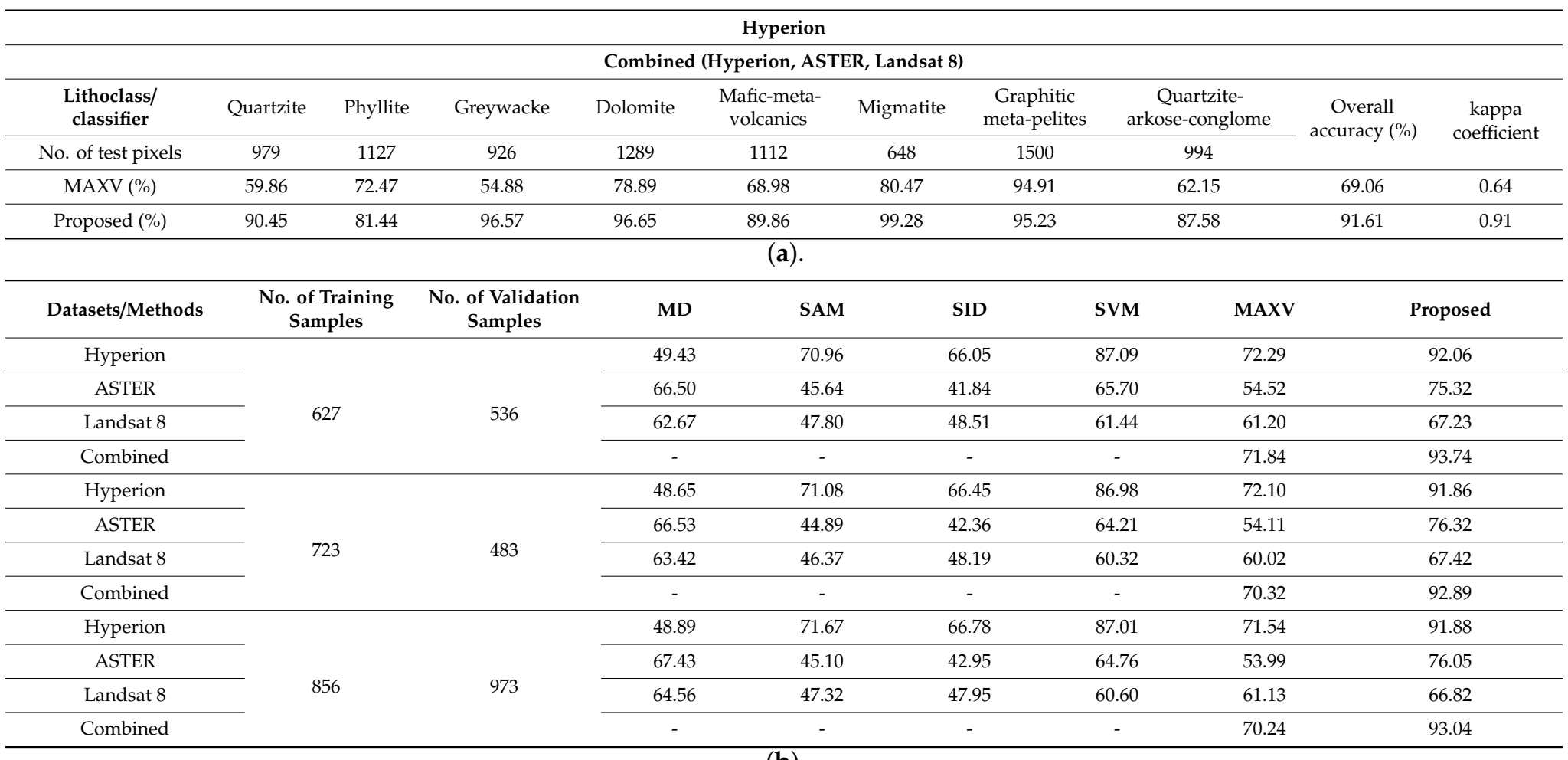


Table 2. Average image quality indices of the study area.

\begin{tabular}{ccccc}
\hline & Data & Hyperion & ASTER & Landsat 8 \\
\hline \multirow{2}{*}{$\begin{array}{c}\text { Statistical } \\
\text { parameters }\end{array}$} & Signal-to-noise ratio & 20.752 & 46.142 & 68.294 \\
\cline { 2 - 5 } & Shannon's entropy & 4.102 & 2.949 & 4.175
\end{tabular}

Note: Robustness of difference classifiers to classify remote sensing images is independence from the quality of the image and spectral distinctiveness. In this paper, image quality indices and spectral statistics (spectral distance and spectral difference) are calculated to understand the importance of remote sensing data quality and spectral distinctiveness in lithological mapping of a study area apart from robustness of the classifiers.

To understand the spectral distinctiveness of training samples, the spectral statistics (spectral distance and weighted spectral difference) [65] have been calculated between average spectra from all training samples and average spectra from individual training samples of different litho-classes of the study area. The spectral distance is calculated as follows:

$$
d=\sqrt{\sum_{i=1}^{n}\left(y_{i}-r_{i}\right)^{2}}
$$

where $d$ is the spectral distance, $r_{i}$ and $y_{i}$ are average reflectance in band $i$ from all and individual training samples of the lithological units respectively, and $n$ is the number of spectral bands.

The spectral difference is calculated as follows:

$$
D=\frac{\sum_{i=1}^{n} y_{i}-r_{i}}{\sum_{i=1}^{n}\left\|y_{i}-r_{i}\right\|}
$$

where $D$ is the spectral difference, $r_{i}$ and $y_{i}$ are average reflectance in band $i$ from all training samples and individual training samples of the lithological units respectively, and $n$ is the number of spectral bands.

Figure 3 and Table 1a,b show that, lithological mapping from the Hyperion image approve that the SAM and the SID produce approximately similar classification accuracies for quartzite, greywacke and graphitic meta-pelites (2-5\%), and for mafic meta-volcanics, migmatite and quartzite-arkose-conglome varies moderately (6-9\%), whereas for phyllite and dolomite varies significantly (15-25\%). The MD produces poor classification accuracy for all classes except phyllite and graphitic meta-pelites in comparison to the SAM and SID for Hyperion image. The MD produces better classification accuracy for phyllite than SID but lower than SAM, whereas the MD produces better classification accuracy for graphitic meta-pelites than the SID and SAM. However, SVM produces slightly better classification accuracies for all the litho-classes than the MD, SAM and SID. The MAXV based ensemble produces better classification accuracies for greywacke and graphitic meta-pelites than SAM, MD and SID, whereas poor classification accuracy is obtained for quartzite than SID and SVM, poor classification accuracies for phyllite, dolomite and quartzite-arkose-conglome than SAM and SVM. Furthermore, the proposed ensemble method produces better classification accuracies for all the litho-units compared to all the above classifiers and the MAXV ensemble-based method from Hyperion image. Finally, overall classification accuracy and kappa coefficient indicate that the proposed method produces highest lithological accuracy among the above classifiers and the MAXV method. However, the ensemble based MAXV method even produces lesser litho-units classification accuracies than the SVM and SAM from the Hyperion image of the study area.

The lithological mapping from the ASTER image shows that the SAM and SID produce approximately similar classification accuracies for phyllite, greywacke and quartzite-arkose-conglome $(2-5 \%)$ and varies moderately $(5-9 \%)$ for mafic quartzite, dolomite and mafic meta-volcanics, whereas for graphitic meta-pelites it varies significantly (approx. 22\%). For these ASTER data the MD produces better classification accuracy compared to the SAM and SID for approximately all the lithologic classes. The MD produces better classification accuracies for quartzite, greywacke, mafic meta-volcanics, migmatite and quartzite-arkose-conglome (6-12\%) than SVM, whereas SVM produces 
better classification accuracies for phyllite, dolomite and graphitic meta-pelites (1-7\%). The MD produces slightly better classification accuracy for all the litho-units compared to SAM, SID and SVM. The MAXV based ensemble produces better classification accuracies for all the litho-units compared to SID and SAM, whereas poor classification accuracies compared to MD and SVM for all the litho-units except for graphitic meta-pelites, which has good bedrock exposure and more diverse (spectral distance and spectral difference) spectra than others. However, the proposed ensemble method produces better classification accuracies for all the litho-units compared to all the classifiers and MAXV method.

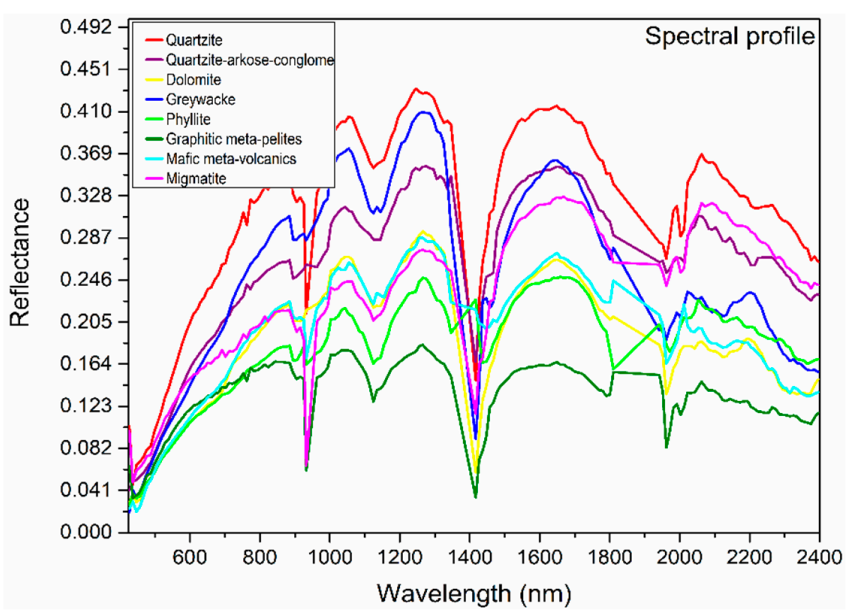

(a)

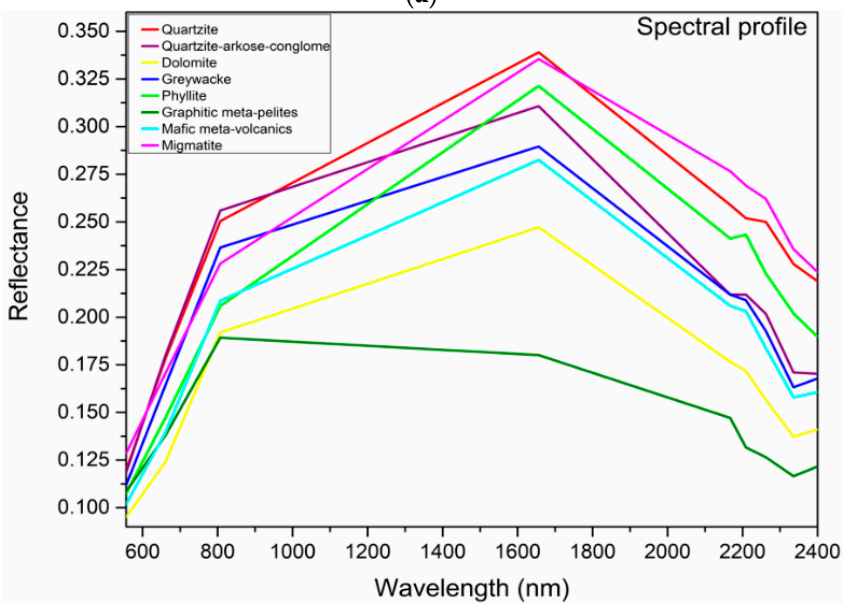

(b)

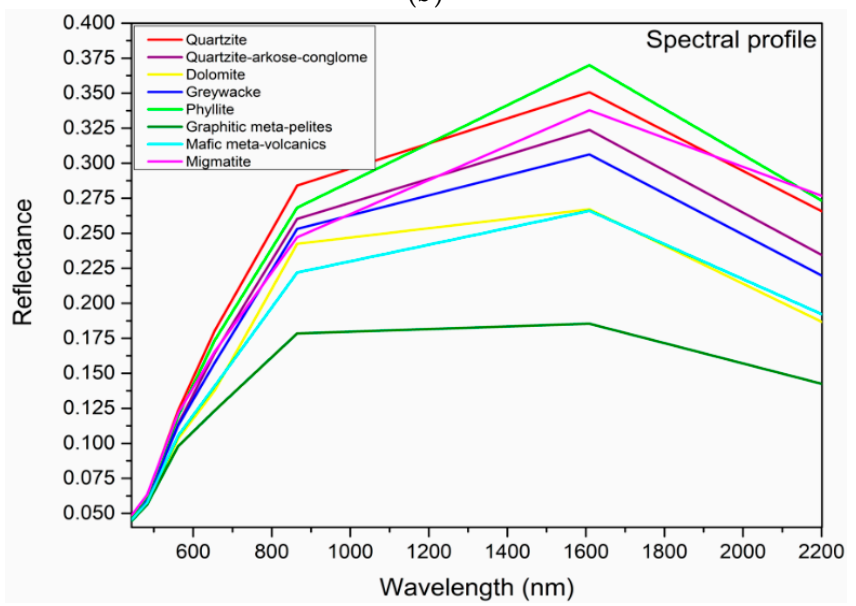

(c)

Figure 4. Average reflectance spectra of training samples from different rock units from exposed terrain from Hyperion image (a), ASTER image (b), and Landsat 8 image (c). 
Table 3. Average spectral statistics of the training samples.

\begin{tabular}{ccccccc}
\hline \multirow{2}{*}{ Lithological Units } & \multicolumn{2}{c}{ Hyperion } & \multicolumn{2}{c}{ ASTER } & \multicolumn{2}{c}{ Landsat 8 } \\
\cline { 2 - 7 } & $\begin{array}{c}\text { Spectral } \\
\text { Difference }\end{array}$ & $\begin{array}{c}\text { Spectral } \\
\text { Distance }\end{array}$ & $\begin{array}{c}\text { Spectral } \\
\text { Difference }\end{array}$ & $\begin{array}{c}\text { Spectral } \\
\text { Distance }\end{array}$ & $\begin{array}{c}\text { Spectral } \\
\text { Difference }\end{array}$ & $\begin{array}{c}\text { Spectral } \\
\text { Distance }\end{array}$ \\
\hline Quartzite & 1.00 & 1.35 & 1.00 & 0.12 & 1.00 & 0.08 \\
\hline Phyllite & -0.97 & 0.61 & 0.70 & 0.07 & 1.00 & 0.09 \\
\hline Greywacke & 0.80 & 0.67 & -0.12 & 0.03 & 0.61 & 0.01 \\
\hline Dolomite & -0.99 & 0.49 & -1.00 & 0.11 & -1.00 & 0.06 \\
\hline $\begin{array}{c}\text { Mafic-meta- } \\
\text { volcanics }\end{array}$ & -0.94 & 0.42 & -1.00 & 0.04 & -1.0 & 0.06 \\
\hline Migmatite & 0.40 & 0.54 & 1.00 & 0.14 & 1.00 & 0.07 \\
\hline $\begin{array}{c}\text { Graphitic-meta- } \\
\text { pelites }\end{array}$ & -0.99 & 1.25 & -1.00 & 0.19 & -1.00 & 0.16 \\
\hline $\begin{array}{c}\text { Quartzite-arkose- } \\
\text { conglome }\end{array}$ & 0.99 & 0.61 & 0.74 & 0.05 & 0.98 & 0.03 \\
\hline
\end{tabular}

Note: Figure 4 is not the laboratory spectra representative of the lithology in general. All the absorption features in remote sensing spectra are modified due to minor components of clay and other hydrated minerals from weathering rather than the lithology themselves (e.g., quartzite with mostly quartz should not have absorption features in this wavelength range, but the spectra do show various absorptions) and nongeological components.

Finally, overall classification accuracy and kappa coefficient indicate that the proposed method produces highest lithological accuracy among all the classifiers and MAXV, whereas the MAXV ensemble-based method produces lesser litho-units classification accuracies compared to SVM and MD from the ASTER image of the study area.

The lithological mapping from the Landsat 8 image shows that the SAM and the SID produce similar classification accuracy for all the litho-units (0-5\%) except greywacke (approx. 11\%). The SID produces better classification accuracy than SAM for greywacke, which has poor bedrock exposure in the study area. The MD produces better classification results compared to SAM and SID for approximately all the lithologic classes. The MD and SVM produce roughly similar classification accuracies for quartzite and graphitic meta-pelites $(0-5 \%)$, whereas the MD produces moderately better classification accuracies for greywacke, mafic meta-volcanics, migmatite and quartzite-arkose-conglome (6-14\%) compared to SVM, whereas SVM produces better classification accuracies for phyllite and dolomite (6-8\%) compared to MD. The MD generally produces better classification accuracies for overall litho-classes compared to SAM, SID and SVM. The MAXV produces better classification accuracies for all the litho-units compared to SID and SAM, whereas it produces poorer classification accuracies for greywacke, dolomite, mafic meta-volcanics and migmatite while producing better classification accuracies for phyllite, quartzite-arkose-conglome and graphitic meta-pelites compared to MD and SVM. However, the proposed method for Landsat 8 also produces better classification accuracy for all the litho-units compared to MD, SAM, SID, SVM and MAXV. Finally, overall classification accuracy and kappa coefficient indicate that the proposed method produces the highest lithological accuracy among the individual classifiers and MAXV. However, MAXV ensemble-based method even produces lesser lithological accuracy than the SVM and MD from the Landsat 8 image of the study area.

The lithological mapping from the combined Hyperion, ASTER and Landsat 8 images also show the similar results as the individual images for both MAXV and the proposed methods. The MAXV from combined images shows better classification accuracy for all litho-classes compare to accuracies obtained from induvial ASTER and Landsat 8 images by different classifiers. However, the MAXV produces poorer litho-classes accuracy from combined images compare to Hyperion image litho-classes accuracy from individual SAM, SID and SVM classifiers. The class-accuracy, overall-accuracy as well as kappa coefficient verify that the proposed method produces highest classification accuracy from individual images as well as from all the images for lithological mapping of the study area. 


\section{Discussion}

It is noticed from class-accuracy, overall accuracy and kappa coefficient that the SVM is a better individual classifier for the Hyperion image whereas MD is a better classifier for the ASTER and Landsat 8 images. It is found that the SAM and SID are considerably better than the MD for the Hyperion image, whereas poorer than the MD for the ASTER and Landsat 8 images. The MD for the Hyperion, SAM for the Landsat 8 and SID for the ASTER are the weakest among employed classifiers, respectively, whereas SVM is the best classifier for the Hyperion, and the better classifier for the ASTER and Landsat 8 images. Thus, it can be concluded that none of the single classifiers discussed above is better for all images (Hyperion, ASTER, and Landsat 8) in lithological mapping. The results from Figure 3 and Table $1 \mathrm{a}, \mathrm{b}$ show that the proposed method enhanced the classification accuracy from the individual images as well as from the combined images. It is also clear that all the litho-classes and overall lithological accuracy obtained by the proposed method applied to the Hyperion image are better compared to ASTER and Landsat 8 images, while additional improvement achieved by combined images (Hyperion, ASTER, Landsat 8), which likewise confirmed that the proposed method is effective in enhancement of classification accuracy in lithological mapping by multiple images. Thus, there is a probability to get enhancement in the accuracy by proposed method higher than the highest accuracy obtained by a single image by inclusion of an extra images.

Spectra from the Hyperion image (Figure 4a) and spectral statistics (Table 3) of migmatite and graphitic meta-pelites are more distinguishable compared to other litho-unit's spectra, whereas quartzite and quartzite-arkose-conglome show the least spectrally distinct in the spectral profile than the rest of the litho-unit's spectra. The litho-unit's spectra from Figure $4 \mathrm{a}$ and spectral statistics from Table 3, and associated classification accuracies from Table 1a,b (Hyperion) reflect the correlation between the spectral distinctiveness and their corresponding classification accuracies. Approximately, all the classifiers show that more distinct litho-unit spectra produce better classification accuracy compared to the other lesser spectrally distinct litho-units [Figure 4a; Table 3; Table 1a,b (Hyperion)]. Spectral profile from ASTER image (Figure $4 \mathrm{~b}$ ) and spectral statistics (Table 3 ) of dolomite and graphitic meta-pelites are more distinct compare to other litho-unit's spectra, whereas quartzite, greywacke and quartzite-arkose-conglome show the lesser separability in the spectral profile compare to the rest of the litho-unit's spectra. The litho-unit's spectra from Figure $4 \mathrm{~b}$, spectral statistic from Table 3 and their classification accuracies from Table $1 \mathrm{a}, \mathrm{b}$ (ASTER) also reflect approximately the similar correlation between the spectral distinguishability and classification accuracies similar as Hyperion. All the classifiers from ASTER also show that more distinct litho-units spectra produce better classification accuracies compared to the other lesser distinct spectra [Figure 4b; Table 3; Table 1a,b (ASTER)]. Spectral profile from Landsat 8 image (Figure 4c) and spectral statistics (Table 3) of migmatite and graphitic meta-pelites have more spectrally discrete than other litho-unit's spectra whereas quartzite, greywacke and quartzite-arkose-conglome show the lesser distinctness in the spectral profile. In Figure $4 \mathrm{c}$ and Table 3 dolomite and mafic meta-volcanics spectra are more disparate than other litho-units except graphitic meta-pelites, but dolomite shows better classification accuracy whereas mafic meta-volcanics shows poor classification accuracy [Table 1a,b (Landsat 8)]. The dolomite shows better bedrock exposure than the mafic meta-volcanics in the study area. This reveals that more exposed rock has better classification accuracy than rock with lesser bedrock exposure. In addition, dolomite is less weather-prone than mafic meta-volcanics, which could be another reason for better surface exposer and thus better detected by optical remote sensing. The litho-unit's spectra from Figure 4c, spectral statistics from Table 3 and their classification accuracies from Table 1a,b (Landsat 8) reflect that more distinguishable spectra of litho-units produce better classification accuracies. All the classifiers from Landsat 8 also show that more distinguishable litho-units spectra produce better classification accuracies compared to the other lesser distinguishable spectra [Figure 4c; Table 3; Table 1a,b (Landsat 8)]. In the case of meta-volcanic classification accuracy also reflect the proportionality with respect to the weathered condition and the related area of the bedrock exposure. Similar outcomes are seen in lithological accuracy from Hyperion and ASTER as Landsat 8 above, in terms of spectral separability, 
weathering nature of litho-unit and extension of the bedrock exposed area associated to the litho-unit, excluding robustness of the classifiers. It is also noted from Figure 3, Table 1a,b, Figure 4, and Table 3 that the litho-units have better classification accuracy for better bedrock exposure even with similar spectral distance and spectral difference from all the images (Hyperion, ASTER, Landsat 8).

Thus, a comparison of the classification images (Figure 3) and their corresponding lithological accuracies (Table 1a,b), average litho-unit's spectra (Figure 4), and spectral statistics (spectral distance and spectral difference) (Table 3) show that the lithological accuracy of a study area from remote sensing images is a proportionate function of the spectral distinctness in the reflectance spectra, resistant to weathering, and extent of the bedrock exposures vis-à-vis to the lithological units in addition to the robustness of the image classifiers. Further, average image quality indices of the Hyperion, ASTER and Landsat 8 have been determined from all the bands, which are shown in Table 2. The signal to noise ratio indicates the quality of the data and Shannon's entropy reveals the information richness in the data. The Landsat 8 have highest whereas the Hyperion have least signal to noise ratio. It is also noticed that Landsat 8 has highest Shannon's entropy, whereas ASTER data have the least Shannon's entropy. Also, the average image quality indices, calculated from all the bands of the image, show that Landsat 8 is strongest in information content and data quality whereas ASTER have poorer data quality and information richness compared to Hyperion and Landsat 8. The overall accuracy and kappa coefficient from all the datasets reveal that classification accuracies are also proportional to the data-quality and information contents in addition to the robustness of the image classifiers.

In summary, lithological mapping accuracy of a study area using optical remote sensing not only depends on the spatio-spectral resolution of the data and robustness of the classification algorithms but also rely on the nature of lithological units and their mineral compositions, susceptibility to weathering, dissimilarities in litho-units reflectance spectra and non-linear spectral mixing, and the data quality. The developed approach considers all the above possibilities to enhance the accuracy in lithological mapping using optical remote sensing data of a study area.

\section{Conclusions}

The complexity and restricted data quality in hyperspectral and multispectral remote sensing images, and limited robustness in single classification algorithms lead to the development of ensemble-based techniques for geological mapping using multi-classifiers. Therefore, in this study, we have developed a hybrid classification procedure involving an ensemble of classifiers (MD, SAM, SID, SVM) to optimize lithological mapping from hyperspectral (Hyperion) and multispectral images (ASTER, Landsat 8). The technique is implemented in four steps. First, classification images are generated using a variety of classifiers. Second, accuracy assessments are performed for each class, overall classification and kappa coefficient, for every classifier. Third, an overall within-class accuracy index is estimated by weighting class accuracy, overall accuracy and kappa coefficient for each class and every classifier. Finally, each pixel of the image is assigned to a class for which it has the highest overall within-class accuracy index amongst all classes in all classifiers. The method is tested on the Hyperion, ASTER and Landsat 8 images from the study area and validated using mixed classification from multi-classifiers (MD, SAM, SID, and SVM) of multiple images (Hyperion, ASTER and Landsat 8). It is observed from the results that the classification accuracy is mainly dependent on the nature of lithological classes and their mineral compositions, diversities in reflectance spectra, non-linear spectral mixing, susceptibility to weathering in addition to the classification algorithms and quality of datasets used. The classification results indicate that the method is effective in increasing the accuracy in lithological mapping of the study area.

In future work, integrated hyperspectral data with enhanced spatio-spectral resolution will be generated using existing state-of-the-art image fusion technique from available multi-sensor hyperspectral and multispectral remote sensing data, which can perform improved accuracy than all available individual data in mineral and lithological mapping of a study area. 
Author Contributions: All authors have made significant contributions to the manuscript. Conceptualization, M.P.; methodology, M.P.; software, M.P., T.R. and A.P.; writing—original draft preparation, M.P.; writing—review and editing, M.P., T.R. and A.P.; formal analysis, M.P., A.P., T.R.; validation, M.P., T.R. and A.P.; data curation, M.P., T.R. and A.P.; funding acquisition, M.P., T.R. and A.P.; supervision, M.P., A.P. and T.R.; project administration, M.P., T.R. and A.P. All authors have read and agreed to the published version of the manuscript.

Funding: This research received no external funding.

Acknowledgments: The authors would like to thank National Aeronautics and Space Administration (NASA) and United States Geological Survey (USGS) for acquiring and providing the data used in this study. We also acknowledge many helpful discussions with Dr. Mehdi Abdolmaleki at the Department of Earth Science and Environmental Engineering, Luleå University of Technology.

Conflicts of Interest: The authors declare no conflict of interest.

\section{References}

1. Lub, D.; Weng, Q. A survey of image classification methods and techniques for improving classification performance. Int. J. Remote Sens. 2007, 28, 823-870.

2. Atkinson, P.M.; Tatnall, A.R.L. Neural networks in remote sensing. Int. J. Remote Sens. 1997, 18, 699-709. [CrossRef]

3. Bachri, I.; Hakdaoui, M.; Raji, M.; Teodoro, A.C.; Benbouziane, A. Machine Learning Algorithms for Automatic Lithological Mapping Using Remote Sensing Data: A Case Study from Souk Arbaa Sahel, Sidi Ifni Inlier, Western Anti-Atlas, Morocco. ISPRS Int. J. Geo-Inf. 2019, 8, 248. [CrossRef]

4. Chen, Y.; Wu, W.; Zhao, Q. A Bat-Optimized One-Class Support Vector Machine for Mineral Prospectivity Mapping. Minerals 2019, 9, 317. [CrossRef]

5. Li, X.; Tang, Z.; Chen, W.; Wang, L. Multimodal and Multi-Model Deep Fusion for Fine Classification of Regional Complex Landscape Areas Using ZiYuan-3 Imagery. Remote Sens. 2019, 11, 2716. [CrossRef]

6. Meng, Z.; Li, L.; Jiao, L.; Feng, Z.; Tang, X.; Liang, M. Fully Dense Multiscale Fusion Network for Hyperspectral Image Classification. Remote Sens. 2019, 11, 2718. [CrossRef]

7. Othman, A.; Gloaguen, R. Improving lithological mapping by SVM classification of spectral and morphological features: The discovery of a new chromite body in the Mawat ophiolite complex (Kurdistan, NE Iraq). Remote Sens. 2014, 6, 6867-6896. [CrossRef]

8. Li, S.; Song, W.; Fang, L.; Chen, Y.; Ghamisi, P.; Benediktsson, J.A. Deep Learning for Hyperspectral Image Classification: An Overview. IEEE Trans. Geosci. Remote Sens. 2019, 57, 6690-6709. [CrossRef]

9. Foody, G.M.; Arora, M.K. An evaluation of some factors affecting the accuracy of classification by an artificial neural network. Int. J. Remote Sens. 1997, 18, 799-810. [CrossRef]

10. Lawrence, R.; Bunn, A.; Powell, S.; Zmabon, M. Classification of remotely sensed imagery using stochastic gradient boosting as a refinement of classification tree analysis. Remote Sens. Environ. 2004, 90, 331-336. [CrossRef]

11. Belousov, A.I.; Verzakov, S.A.; von Frese, J. A flexible classification approach with optimal generalisation performance: Support vector machines. Chermometrics Intell. Lab. Syst. 2002, 64, 15-25. [CrossRef]

12. Hsu, C.W.; Lin, C.J. A comparison of methods for multi-class Support Vector Machines. IEEE Trans. Neural Netw. 2002, 13, 415-425. [PubMed]

13. Kim, H.; Pang, S.; Je, H.; Kim, D.; Bang, S.Y. Constructing support vector machine ensemble. Pattern Recognit. 2003, 36, 2757-2767. [CrossRef]

14. Li, N.; Huang, X.; Zhao, H.; Qiu, X.; Deng, K.; Jia, G.; Gong, X. A Combined Quantitative Evaluation Model for the Capability of Hyperspectral Imagery for Mineral Mapping. Sensors 2019, 19, 328. [CrossRef] [PubMed]

15. Clark, R.N. Chapter 1-8: Spectroscopy of Rocks and Minerals, and Principles of Spectroscopy. In Manual of Remote Sensing, Remote Sensing for the Earth Sciences; John Wiley and Sons: New York, NY, USA, 1999; Volume 3, pp. 3-58.

16. Zhang, T.; Yi, G.; Li, H.; Wang, Z.; Tang, J.; Zhong, K.; Bie, X. Integrating data of ASTER and Landsat-8 OLI (AO) for hydrothermal alteration mineral mapping in duolong porphyry cu-au deposit, Tibetan Plateau, China. Remote Sens. 2016, 8, 890. [CrossRef]

17. Yokoya, N.; Chan, J.; Segl, K. Potential of resolution-enhanced hyperspectral data for mineral mapping using simulated EnMAP and Sentinel-2 images. Remote Sens. 2016, 8, 172. [CrossRef] 
18. Liu, Y.; Lu, S.; Lu, X.; Wang, Z.; Chen, C.; He, H. Classification of Urban Hyperspectral Remote Sensing Imagery Based on Optimized Spectral Angle Mapping. J. Indian Soc. Remote Sens. 2019, 47, $289-294$. [CrossRef]

19. Noori, L.; Pour, A.B.; Askari, G.; Taghipour, N.; Pradhan, B.; Lee, C.W.; Honarmand, M. Comparison of Different Algorithms to Map Hydrothermal Alteration Zones Using ASTER Remote Sensing Data for Polymetallic Vein-Type Ore Exploration: Toroud-Chahshirin Magmatic Belt (TCMB), North Iran. Remote Sens. 2019, 11, 495. [CrossRef]

20. Van der Meer, F.D.; Bakker, W. Cross correlogram spectral matching (CCSM): Application to surface mineralogical mapping using AVIRIS data from Cuprite, Nevada. Remote Sens. Environ. 1997, 61, 371-382. [CrossRef]

21. Van der Meer, F.D. The effectiveness of spectral similarity measures for the analysis of hyperspectral imagery. Int. J. Appl. Earth Obs. Geoinf. 2006, 8, 3-17. [CrossRef]

22. Van der Meer, F.D. Spectral matching using pixel cross-correlograms for the analysis of LANDSAT TM data. Int. J. Appl. Earth Obs. Geoinf. 2001, 3, 197-202. [CrossRef]

23. Van der Meer, F.D.; De Jong, S. Spectral mapping methods: Many problems, some solutions. In Proceedings of the 3rd EARSeL Workshop on Imaging Spectroscopy, Herrsching, Germany, 13-16 May 2003; pp. 146-162, (Hannover: The European Association of Remote Sensing Laboratories (EARSeL)).

24. Kruse, F.A.; Boardman, J.; Huntington, J. Comparison of Airborne Hyperspectral Data and EO-1 Hyperion for Mineral Mapping. IEEE Trans. Geosci. Remote Sens. 2003, 41, 1388-1400. [CrossRef]

25. Meima, J.A.; Rammlmair, D. Investigation of compositional variations in chromitite ore with imaging Laser Induced Breakdown Spectroscopy and Spectral Angle Mapper classification algorithm. Chem. Geol. 2019, 532, 119376. [CrossRef]

26. Kruse, F.A.; Lefkoff, A.B.; Dietz, J.B. Expert system-based mineral mapping in northern Death Valley, California/Nevada, using the airborne visible/infrared imaging spectrometer (AVIRIS). Remote Sens. Environ. 1993, 44, 309-336. [CrossRef]

27. Wang, Y.; Jiang, Y. A Weighted Minimum Distance Classifier Based on Relative Offset. In Proceedings of the 2019 IEEE 4th International Conference on Cloud Computing and Big Data Analysis (ICCCBDA), Chengdu, China, 12-15 April 2019; pp. 343-347.

28. Du, Y.; Chang, C.I.; Ren, H.; Chang, C.C.; Jensen, J.O.; D'Amico, F.M. New hyperspectral discrimination measure for spectral characterization. Opt. Eng. 2004, 43, 1777-1787.

29. Chang, C.I. Spectral information divergence for hyperspectral image analysis. In Proceedings of the IEEE 1999 International Geoscience and Remote Sensing Symposium. IGARSS'99 (Cat. No. 99CH36293), Hamburg, Germany, 28 June-2 July 1999; Volume 1, pp. 509-511.

30. Kopačková, V.; Koucká, L. Integration of absorption feature information from visible to longwave infrared spectral ranges for mineral mapping. Remote Sens. 2017, 9, 6. [CrossRef]

31. Kruse, F.A.; Taranik, J.V.; Coolbaugh, M.; Michaels, J.; Littlefield, E.F.; Calvin, W.M.; Martini, B.A. Effect of reduced spatial resolution on mineral mapping using imaging spectrometry-Examples using Hyperspectral Infrared Imager (HyspIRI)-simulated data. Remote Sens. 2011, 3, 1584-1602. [CrossRef]

32. Kruse, F.; Perry, S. Mineral mapping using simulated Worldview-3 short-wave-infrared imagery. Remote Sens. 2013, 5, 2688-2703. [CrossRef]

33. Clark, R.N.; Roush, T.L. Reflectance spectroscopy: Quantitative analysis techniques for remote sensing applications. J. Geophys. Res. 1984, 89, 6329-6340. [CrossRef]

34. Kokaly, R.F.; Clark, R.N. Spectroscopic determination of leaf biochemistry using band depth analysis of absorption features and stepwise multiple linear regression. Remote Sens. Environ. 1999, 67, 267-287. [CrossRef]

35. Mutanga, O.; Skidmore, A.K. Hyperspectral band depth analysis for a better estimation of grass biomass (Cenchrus ciliaris) measured under controlled laboratory conditions. Int. J. Appl. Earth Obs. Geoinf. 2004, 5, 87-96. [CrossRef]

36. Crowley, J.K.; Brickey, D.W.; Rowan, L.C. Airborne imaging spectrometer data of the Ruby mountains, Montana: Mineral discrimination using relative absorption band-depth images. Remote Sens. Environ. 1989, 29, 121-134. [CrossRef] 
37. Van Ruitenbeek, F.J.; Debba, P.; van der Meer, F.D.; Cudahy, T.; van der Meijde, M.; Hale, M. Mapping white micas and their absorption wavelengths using hyperspectral band ratios. Remote Sens. Environ. 2006, 102, 211-222. [CrossRef]

38. Clark, R.N.; Swayze, G.A. Mapping minerals, amorphous materials, environmental materials, vegetation, water, ice, and snow, and other materials: The USGS Ticorder Algorithm. In Proceedings of the Summaries of the Fifth Annual JPL Airborne Earth Science Workshop 1995, Pasadena, CA, USA, 23-26 January 1995; Jet Propulsion Laboratory Publication: Pasadena, CA, USA, 1995; Volume 1, pp. 39-40.

39. Clark, R.N.; Swayze, G.A.; Gallagher, A. Mapping the mineralogy and lithology of Canyonlands, Utah with imaging spectrometer data and the multiple spectral feature mapping algorithm. In Proceedings of the Summaries of the Third Annual JPL Airborne Geoscience Workshop 1992, Pasadena, CA, USA, 1-5 June 1992; Jet Propulsion Laboratory Publication: Pasadena, CA, USA, 1992; Volume 1, pp. 11-13.

40. Clark, R.N.; Swayze, G.A.; Livo, K.E.; Kokaly, R.F.; Sutley, S.J.; Dalton, J.B.; McDougal, R.R.; Gent, C.A. Imaging spectroscopy: Earth and planetary remote sensing with the USGS Tetracorder and expert systems. J. Geophys. Res. 2003, 108, 1-44. [CrossRef]

41. Pan, Z.; Huang, J.; Wang, F. Multi range spectral feature fitting for hyperspectral imagery in extracting oilseed rape planting area. Int. J. Appl. Earth Obs. Geoinf. 2013, 25, 21-29. [CrossRef]

42. Settle, J.J.; Drake, N.A. Linear mixing and the estimation of ground cover proportions. Int. J. Remote Sens. 1993, 14, 1159-1177. [CrossRef]

43. Duan, P.; Li, J.; Lu, X.; Feng, C. Estimation of Impervious Surface Distribution by Linear Spectral Mixture Analysis: A Case Study in Nantong, China. In Proceedings of the 2nd EAI International Conference on Robotic Sensor Networks, Kitakyushu, Japan, 25-26 August 2018; Springer: Cham, Switzerland, 2020; pp. 41-51.

44. Weng, Q.; Lub, D. A sub-pixel analysis of urbanization effect on land surface temperature and its interplay with impervious surface and vegetation coverage in Indianapolis, United States. Int. J. Appl. Earth Obs. Geoinf. 2008, 10, 68-83. [CrossRef]

45. Hapke, B. Bidirectional reflectance spectroscopy: 1. Theory. J. Geophys. Res. Solid Earth 1981, 86, 3039-3054. [CrossRef]

46. Hapke, B. Theory of Reflectance and Emittance Spectroscopy; Cambridge University Press: New York, NY, USA, 2012.

47. Hapke, B.; Wells, E. Bidirectional reflectance spectroscopy: 2. Experiments and observations. J. Geophys. Res. Solid Earth 1981, 86, 3055-3060. [CrossRef]

48. Guilfoyle, K.J.; Althouse, M.L.; Chang, C.I. A quantitative and comparative analysis of linear and nonlinear spectral mixture models using radial basis function neural networks. IEEE Geosci. Remote Sens. Lett. 2001, 39, 2314-2318. [CrossRef]

49. Altmann, Y.; Halimi, A.; Dobigeon, N.; Tourneret, J.Y. Supervised nonlinear spectral unmixing using a postnonlinear mixing model for hyperspectral imagery. IEEE Trans. Image Process. 2012, 21, 3017-3025. [CrossRef] [PubMed]

50. Broadwater, J.; Chellappa, R.; Banerjee, A.; Burlina, P. Kernel fully constrained least squares abundance estimates. In Proceedings of the 2007 IEEE International Geoscience and Remote Sensing Symposium (IGARSS), Barcelona, Spain, 23-28 July 2007; pp. 4041-4044.

51. Tran, D.; Bourdev, L.; Fergus, R.; Torresani, L.; Paluri, M. Learning spatiotemporal features with 3d convolutional networks. In Proceedings of the IEEE International Conference on Computer Vision, Santiago, Chile, 13-16 December 2015; pp. 4489-4497.

52. Zhou, B.; Lapedriza, A.; Xiao, J.; Torralba, A.; Oliva, A. Learning deep features for scene recognition using places database. In Advances in Neural Information Processing Systems 27 (NIPS 2014), Proceedings of the Annual Conference on Neural Information Processing Systems 2014, Montreal, QC, Canada, 8-13 December 2014; MIT Press: Cambridge, MA, USA, 2014; pp. 487-495.

53. Jaakkola, T.; Haussler, D. Exploiting generative models in discriminative classifiers. In Advances in Neural Information Processing Systems 11 (NIPS 1998), Proceedings of the Annual conference on Neural Information Processing Systems 1998, Denver, CO, USA, 1-3 December 1998; MIT Press: Cambridge, MA, USA, 1998; pp. 487-493.

54. Melgani, F.; Bruzzone, L. Classification of hyperspectral remote sensing images with support vector machines. IEEE Trans. Geosci. Remote Sens. 2004, 42, 1778-1790. [CrossRef] 
55. Gislason, P.O.; Benediktsson, J.A.; Sveinsson, J.R. Random forests for land cover classification. Pattern Recognit. Lett. 2006, 27, 294-300. [CrossRef]

56. Rodriguez-Galiano, V.F.; Ghimire, B.; Rogan, J.; Chica-Olmo, M.; Rigol-Sanchez, J.P. An assessment of the effectiveness of a random forest classifier for land-cover classification. ISPRS J. Photogramm. Remote Sens. 2012, 67, 93-104. [CrossRef]

57. Heron, A.M. The geology of central Rajputana. Mem. Geol. Surv. Ind. 1953, 79, 1-389.

58. Roy, A.B.; Kataria, P. Precambrian geology of the Aravalli Mountains and neighborhood: Analytical update of recent studies. In Proceedings of the Seminar on Geology of Rajasthan-Status E Perspective; Kataria, P., Ed.; Geology Deptt., MLSU: Udaipur, India, 1999; pp. 1-250.

59. Beck, R. EO-1 User Guide; Version 2.3; University of Cincinnati: Cincinnati, OH, USA, 2003.

60. Gupta, S.N.; Arora, Y.K.; Mathur, R.K.; Iqballuddin; Prasad, B.; Sahai, T.N.; Sharma, S.B. The Precambrian geology of the Aravalli region, southern Rajasthan and north-eastern Gujarat. Mem. Geol. Surv. Ind. 1997, 123, 1-262.

61. Gupta, S.N.; Arora, Y.K.; Mathur, R.K.; Iqballuddin; Prasad, B.; Sahai, T.N.; Sharma, S.B. Lithostratigraphic Map of Aravalli Region (1:250,000), 2nd ed.; Geological Survey of India Press: Calcutta, India, 1995; 4 sheets.

62. Tobler, W. A computer movie simulating urban growth in the Detroit region. Econ. Geogr. 1970, 46 (Suppl. 1), 234-240. [CrossRef]

63. Zhu, B.; Wang, X.; Li, Z.; Dou, S.; Tang, L.; Li, C. A new method based on Spatial Dimension Correlation and Fast Fourier Transform for SNR estimation in remote sensing images. In Proceedings of the 2013 Geoscience and Remote Sensing Symposium (IGARSS-2013), Melbourne, Victoria, Australia, 21-26 July 2013; pp. 4114-4117.

64. Lidong, G.; Guoqing, L. Research on method of remote sensing data quality contrast among different quantization levels. In Proceedings of the 2013 the International Conference on Remote Sensing, Environment and Transportation Engineering (RSETE 2013), Nanjing, China, 26-28 July; Atlantis Press Paris: Paris, France; Volume 31, pp. 729-732.

65. Yang, C.; Everitt, J.H. Using spectral distance, spectral angle and plant abundance derived from hyperspectral imagery to characterize crop yield variation. Precis. Agric. 2012, 13, 62-75. [CrossRef]

(C) 2020 by the authors. Licensee MDPI, Basel, Switzerland. This article is an open access article distributed under the terms and conditions of the Creative Commons Attribution (CC BY) license (http://creativecommons.org/licenses/by/4.0/). 